\title{
A comparative review of Nettle and Ramie fiber and their use in biocomposites, particularly with a PLA matrix
}

\author{
Fabien Bogard ${ }^{\text {a* }}$, Thierry Bach ${ }^{\mathrm{b}}$, Boussad Abbes ${ }^{\mathrm{a}}$, Christophe Bliard ${ }^{\mathrm{c}}$, Chadi Maalouf ${ }^{\mathrm{a}}$, \\ Virginie Bogard $^{\mathrm{a}}$, Fabien Beaumont ${ }^{\mathrm{a}}$, and Guillaume Polidori ${ }^{\mathrm{a}}$ \\ (a) Faculty of Exact and natural Sciences, University of Reims Champagne Ardenne, France \\ (b) National School of Mechanics and Aerotechnics, Poitiers, France \\ (c) ICMR-UMR 7312 CNRS, SFR Condorcet FR CNRS 3417, University of Reims \\ Champagne Ardenne, France \\ * Corresponding author: fabien.bogard@univ-reims.fr
}

\begin{abstract}
Current environmental concerns are increasingly forcing manufacturers to reduce the use of petroleum derivatives in order to reduce their carbon footprint. The use of new plant-based materials is therefore an interesting alternative to plastics. A certain number of plant fibers have been rediscovered for use in the form of agro-composites; Nettle fiber is one of them. The objective of this review is thus to take stock of current knowledge on the European Nettle fiber (Urtica Dioica) and its asian version (Boehmeria nivea, or Ramie), which are too often confused. This "weed", which has been used since antiquity, is coming back into fashion thanks to the highlighting of some of its properties but also to its simplicity of cultivation. The association PLA/Nettle, lending itself perfectly to this concept of modern ecological material $100 \%$ biodegradable, is also highlighted in this work where the intrinsic qualities of each component are detailed based on the promising uses of this agro-composite mentioned in the literature or the automotive industry.
\end{abstract}

\section{KEYWORDS}

stinging nettle, polylactic acid, mechanical characteristics, biodegradable, treatment, automotive

\section{Introduction}

Nettle and Ramie both belong to the Urticaceae family, but they are from different genus, (Hassler 2018). They are both structured around a long stem carrying the leaves (Table 1). The stem length is different between the two species with Ramie's stem generally measuring above 2 meters while Nettle's stems are more likely ranging from 1 meter or more. The growing interest around these plants is mainly due to their fiber. Indeed, Nettle and Ramie contain fibers, which allow them to have these long stems while being straights. With recent concerns around climate changes, resources savings and constant need for technological progress, researchers are leading new studies to better characterize these biomaterials and replace their petroleum-based counterparts (Abbès et al. 2020 or Karaky et al. 2019). Ramie and Nettle advantages have been known for centuries, their mechanical and biological properties were used in the cloth industry as well as in medicine (Allais 2019; Draghy 2005; Upton 2013).

First known traces of Nettle are from 2800 years ago in Denmark where Nettle clothes were used for burial of human remains while first evidence of Ramie come from Egypt during 5000-3000 BC (Du et al. 2015) even if there is no records of its use. In Asia, Ramie fibers were used to produce clothes, paper and drugs. A medicinal use-in Europe is reported (Draghy 2005) especially with Romans, as Nettle fibers is efficient to treat usual diseases (treatment of joint pain and water elimination in kidneys for instance). This knowledge disappeared largely during the 17th century, before being rediscovered in the 19th century. Nettle fibers were widely used in the army during the First World War to produce bag pack, tents, underwear, 
socks and $85 \%$ of soldier clothes (Bodros and Baley 2008; Koronis et al. 2013). More recently, even though these fibers have a really high potential for different application, difficulties to mechanize the different processes and growing labor costs have led to abandon Nettle fibers to the benefit of other bast fibers such as flax and hemp. Nevertheless, Nettle great mechanical potential is known and the current motivations around carbon footprint reduction have led to consider their use into the creation of composite materials that are more environment friendly. Recent concerns about water consumption of cotton culture also helps to promote other fibers such as flax, hemp and now, Nettle (Rehman et al. 2019).

Table 1. Urticacease family caractristics (Koronis et al. 2013) and Nettle / Ramie pictures.

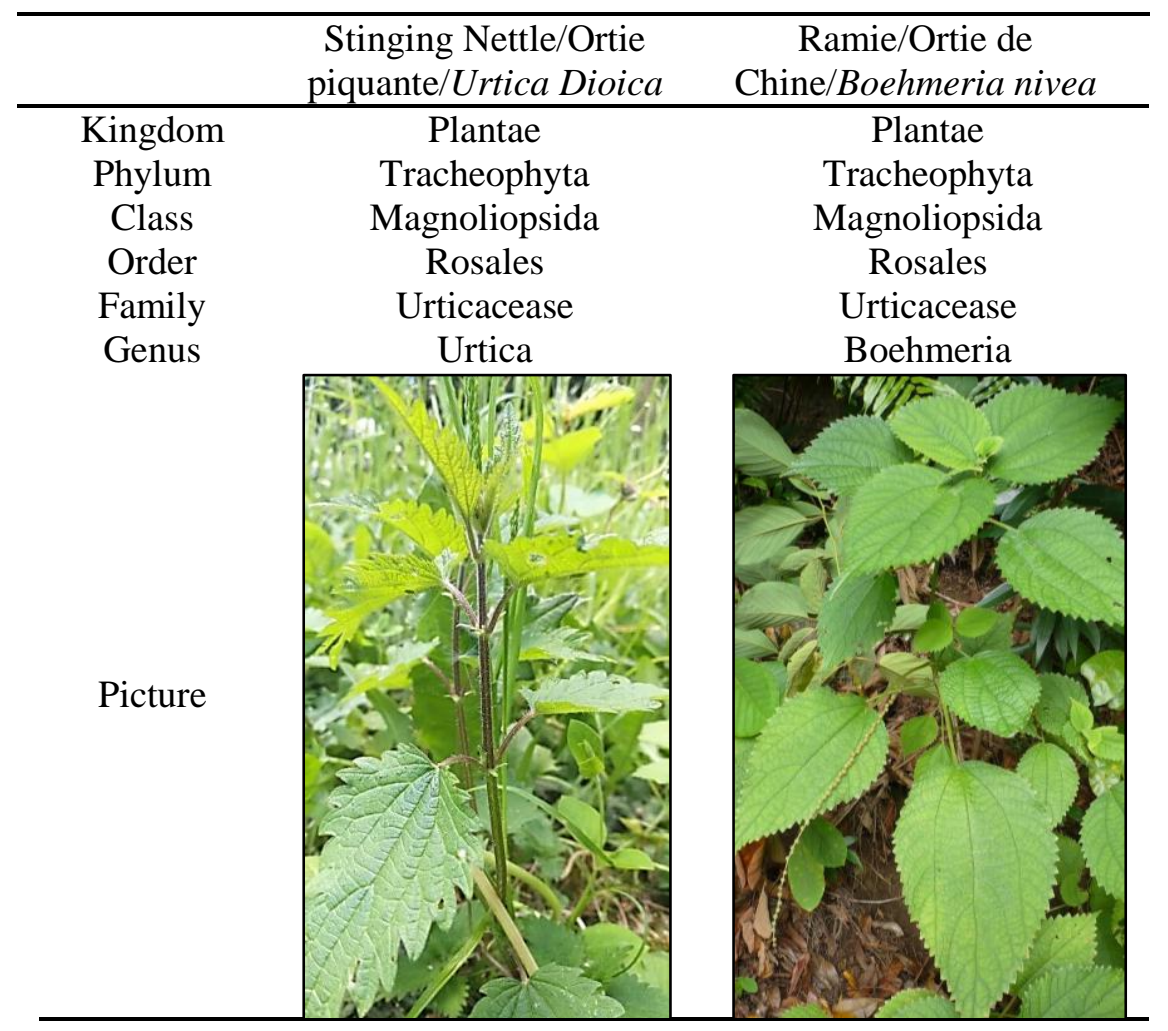

The use of Nettle/Ramie in biocomposite materials are not new since first traces of their use are visible in the Great Wall of China with reeds use as reinforcements in clay walls. More recently, at the beginning of the $19^{\text {th }}$ century, phenolic resin and cotton were associated to make tubes for electronics and later for producing long life mechanical parts such as gears and camshafts (Baley 2013c; Faruk et al. 2012). Industrials were looking for lighter materials than metals with good exterior finish and insensitive to corrosion (Broohm 2018). Despite good results, the arrival of petroleum-based plastics and the apparition of glass and carbon fibers used to produce high quality laminates caused a massive disinterest around biocomposites. Recent concerns caused by climate changes have aroused scientists' interest, therefore leading to numerous studies around biofibers, especially in the late 2010's in Europe with a growth of 5 to $10 \%$ of the demand for biodegradable polymers (Ho et al. 2012). At the same time, the JEC-group schedules a growth of the composite market of 5\% per year until 2021 (JEC 2017). Nowadays, an important literature is available on usual fibers such as hemp, flax, jute, sisal and Ramie but data about Nettle fibers remains anecdotal. This paper proposes a global overview of the main results obtained with Ramie and Nettle fibers, especially when 
associated with PLA, a plastic material of vegetal origin and therefore renewable (Ojodo et al. 2020).

Biocomposites have many advantages over synthetic composites, some are related to the mechanical aspects with a reduced weight compared to usual glass and carbon fibers, other benefits are more related to our society as they are renewable, biodegradable and sustainable materials and are available in huge quantities if needed (Ashori 2008; Bouzouita 2011; CARMA 2006; Do Thi 2011; Li et al. 2007; Nabi et al. 1999; Ogunsona et al. 2019). Nettle and Ramie crops are more expensive to initiate but are a long-term investment as they can last 10-15 years and furthermore the Nettle crop is considered economically viable over 4 years (Di Virgilio 2015). These fibers are also promising as all parts can be used commercially from roots to seeds (Draghy 2005). Moreover, several harvests can occur during the year, a first cut in April can be used for medicinal use or chlorophyll production, then a second cut at the end of June will be beneficial for fiber production while a third cut during the fall will allow the use of leaves. Nevertheless, such intensive culture will result in lower fiber quality and loss of crop vigor as mentioned in (Di Virgilio 2015). Nettle fibers are also particularly beneficial to over fertilized soils as they are nitrophilous, therefore helping to regulate human activities. They are safe to handle and cause far less health problems than synthetic fibers. These materials also resist corrosion and fatigue, therefore meaning that they are well adapted to replace their synthetic counterparts. In addition, biocomposites are easier to process in comparison with synthetic fibers which are really abrasive for cutting tools, but also costly and unsafe for human health (Ashori 2008; Di Virgilio 2015; Holbery and Houston 2006; Loureiro and Esteves 2019). Biocomposite generally need higher fiber ratio than their synthetic counterpart, thus leading to cost reduction as fewer matrix is needed (Summerscales 2010b). One last advantage of biocomposite involving thermoplastics is the possibility to fuse parts together instead of using bolt or standard assembling means (Beardmore 1986). This is a major advantage over metals for instance, as it also reduces the risk of failure due to stress concentration.

However, natural fibers do not only have advantages; they also have drawbacks. Working with natural fibers is really challenging, as there are plenty of parameters to consider. As natural fibers, they are more sensitive to moisture and temperature. Their mechanical properties also vary a lot depending on growing and harvesting conditions or fiber extraction method. Even their composition can cause difficulties, for instance the natural wax they contain renders the adhesion with the matrix more difficult (Verma and Senal 2019). Usually, natural fibers are also scheduled for shorter use than their synthetic counterparts due to higher sensitivity to external environment (Summerscales 2010b). From a soil pollution point of view, fiber cultivation does not prevent some farmers from using fertilizers to increase yields, which can lead to soil eutrophication due to too high concentrations of nitrate and phosphate, but even on this type of soil, Nettle and ramie grow easily. (Summerscales 2010a, 2010b). Another drawback linked to the usage of biocomposite or composite is the uncertainty around the final mechanical properties as it highly depends on the materials involved and on the manufacturing conditions; this is particularly true for the use of natural fibers as reinforcement in a biocomposite. Multiple laws exist to predict these properties and they can be very accurate for some kind of structure such as UD (unidirectional), but sometimes they can deviate and be too optimistic, even with numerical simulations (Barral et al. 2019; Coppo et al. 2017; Eshelby 1957; Ji 2017; Girard et al. 2017; Jain et al. 2017; Moussady 2013; Tucker and Liang 1999).

\section{Vegetal fibers; Nettle fiber}




\section{Nettle fiber culture}

Nettle plants are very common under our latitudes. They can grow everywhere, from a polluted area to a wild forest up to an altitude as high as 2400 meters. Their culture is relatively expensive, as the seedling with Nettle's seeds does not work well due to inhomogeneity resulting from pollination and crossing of species (Sudamrao Getme and Patel 2020; Bacci et al. 2009). One major advantage of Nettle and Ramie culture is the increasing yield with $335 \mathrm{~kg} / \mathrm{ha}$ to $411 \mathrm{~kg} / \mathrm{ha}$ during the second year and $743 \mathrm{~kg} / \mathrm{ha}$ to $1016 \mathrm{~kg} / \mathrm{ha}$ the third year for Nettle fields while it can reach $2000 \mathrm{~kg} / \mathrm{ha}$ for Ramie fiber, (CARMA 2006; Moussady 2013).

Therefore, cutting is the only way to operate the multiplication of the plant correctly, requiring human intervention. But this bigger initial investment is worthy as the Nettle grows again once it has been cut, allowing its cultivation over 10 years. Moreover, Nettle culture requires less water than usual crop culture. According to Draghy (2005), each plant can produce 6 to $8 \%$ of fiber in weight. The main problem consists in the variation of fiber quality from one year to the other as it greatly depends on growing conditions (rain, sunshine, temperature...) as well as on processing conditions. This variability is clearly visible not only in the diameter of the fiber (Bergfjord and Holst, 2010) but also through the mechanical properties of the fiber which differ widely from one study to another. Moreover, the variability is due to morphological parameters such as crystallinity, micro-fibril angle, fineness, porosity, size and shape of the lumen, etc. as well as measurement conditions such as tensile speed, initial gauge length, moisture and temperature, section of the fiber used (Bledzki and Gassan 1999; Shahzad 2017). However, this variability is on the same order as for synthetic fibers produced with the same methods (Torres et al. 2017).

In Europe, there are 11 species of Nettle among which 5 are found in France (Bacquaert 2013). The most represented species is Urtica Dioica also known as stinging Nettle while China's Nettle or Ramie Boehmeria nivea is more represented in Asia. However, there are plenty of Nettle genus in the urtica family, making harder the establishment of average properties.

\section{Nettle fibers extraction}

Like for most of natural fibers, Nettle fibers are located between the central woody core and the outer bark. There are generally concentrated into bundles and held together by pectin. The fiber ratio inside the plant tends to increase in its upper part with values up to $16 \%$ according to Di Virgilio et al. (2015) and Bacci et al. (2009) therefore resulting in variations of mechanical properties, as observed below for flax in Table 2.

Table 2. Fibers caracteristics according to mechanical properties (Gourrier 2016).

\begin{tabular}{cccc}
\hline stem height & Fiber diameter & Lumen size & $\begin{array}{c}\text { Mechanical } \\
\text { properties }\end{array}$ \\
\hline top & + & ++ & ++ \\
middle & ++ & + & +++
\end{tabular}


Once the size of the lumen is acceptable, i.e. once the fiber content is sufficient, the harvest begins. This consists in a succession of steps in order to extract the precious fibers (Figure 1).

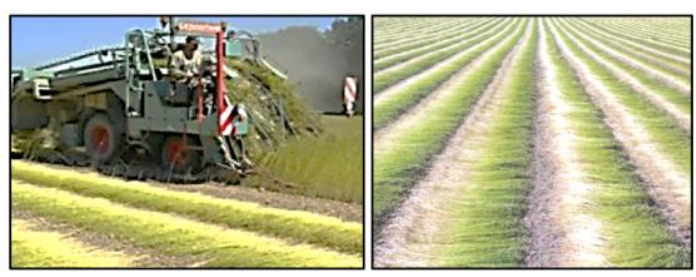

(a)

(b)

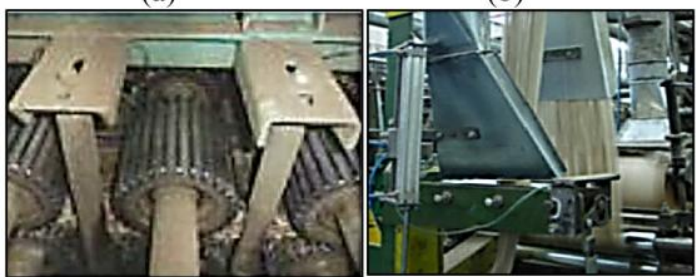

(c)

(d)

Figure 1. Different steps to obtain vegetal fiber: (a) cutting, (b) retting, (c) crushingthreshing, (d) spinning (Astruc 2018; Barbulée 2015; Rouch 2018).

After cutting the plant, the first step is retting. Different processes exist to extract the fiber from the plant stem, unfortunately, most of them involve mechanical extraction, thus resulting in mechanical damages of the fiber. Two methods are generally used for retting: dew retting and water retting. The first one consists in laying the cut stem on the ground a few days to allow the action of fungi and bacteria to degrade pectin and allow an easy separation of fiber from the rest of the plant. The second one is more controlled and therefore more reproducible as it consists in laying the plant stem in tanks filled with well water (Di Virgilio et al. 2015). In general, both methods result in better quality fibers because they ultimately contain less lignin and generate smaller diameter fibers, which benefits the mechanical properties (Asshori 2008; Bodros and Baley 2008). However, water retting involves higher labor costs and disagreement such as fermentation odor and environmental problems due to effluent discharge (Di Virgilio et al. 2015). After the retting, the separation of the fiber from the rest of the stem is easier. This step is called the "decortication" and it consists in the removal of non-fibrous materials. This can be achieved manually or with a hammer mill or an inclined plane/fluted rollers or willower. As Nettle and Ramie contain less lignin than other common bast fibers, the extraction also needs less energy (Fischer et al. 2012). Once extracted, fiber follow different processes relative to the textile industry. These Nettle fibers are mainly used today to make fabrics, clothing, bags or fashion accessories. The final steps in the processing are: carding to align and separate the fibers from each other (this is done with two moving plates covered with spikes), then spinning to stretch and twist the fibers together into a yarn, which can then be used to make different products such as mats or fabrics, just like any other plant fiber. (Summerscales 2010a). 
Natural fibers are hollow and are composed of several layers. The hollow part in the center is called the lumen and it serves to transport the water and nutriments inside the plant (Baley 2013c; Eichhorn et al. 2001; Ho et al. 2012; Kalia et al. 2009). The size of the lumen decreases with time and therefore allows to determine the quality and the maturity of the fiber (Baley 2002a). Then, there are two other layers called primary and secondary walls as mentioned by Dicker et al. (2014) (Figure 2).

Usually, liberian fibers (fibers such as hemp, linen, Ramie, burlap...) have a polygonal section (Gourier 2016), as they are hollow, most of times this section is not axisymmetric, leading to poor evaluation of the external diameter. According to various authors (Bodros and Bailey 2008; Gourier 2016), the average external diameter of Nettle fiber can vary between $20 \mu \mathrm{m}$ and $50 \mu \mathrm{m}$, some fibers have been reported with a maximum diameter of $70 \mu \mathrm{m}$. The diameter of the fiber plays an important role in the mechanical performance as bigger diameter results in lower tensile modulus and lower stress at break (Ashori 2008; ; Barbulée 2015; Bledzki and Gassan 1999; Summerscales 2010a, 2010b). Du et al. (2015) have shown that the resistance of the ramie fiber to its volume follows Weibull's law. The fact that these fibers are hollow also affect the mechanical properties as the exact area of the fiber is not known leading to overestimated values for tensile strength and modulus. I order to take the different porosities into consideration, Laurans et al. (2006) or Madsen et al. (2007a, 2009b) have developed different comportment's laws. The size of the lumen can also increase the overall porosity of a composite because most processes used do not utilize this void, leading to porous materials with significant moisture absorption capabilities that are not necessarily desired.

The secondary wall is the most interesting one considering a mechanical point of view as it contains the micro-fibrils (Figure 2). These micro-fibrils are wrapped around the other layers and form an angle with the longitudinal axis of the fiber angle, which differs from specie to specie (Bouzouita 2011, Eichhorn et al. 2001; Laurans et al. 2006). Ramie micro-fibrils have a $3^{\circ}$ angle according to Bodros and Baley (2008), as Nettle have a rather linear tensile behavior, this angle is therefore supposed to be also low on the contrary to flax fiber whose micro-fibrils form a $10^{\circ}$ angle and which has a non-linear response in traction. The direction of enrollment is S shaped for Nettle, Ramie and flax while it is $\mathrm{Z}$ shaped for other fibers such as hemp or jute (Bergfjord and Holst 2010) (Figure 2). These micro-fibrils are made of cellulose chains embedded in pectin with hemicellulose playing the role of an interface between the two (Kalia et al. 2009). The primary wall contains essentially pectin and a few randomly oriented micro-fibrils.

Therefore, fibers on their own are considered as composite materials as they are constituted of cellulose chains forming micro-fibrils embedded in an organic matrix (Laurens et al. 2006), forming bigger fibrils and finally fibers visible at a microscale (Figure 2).

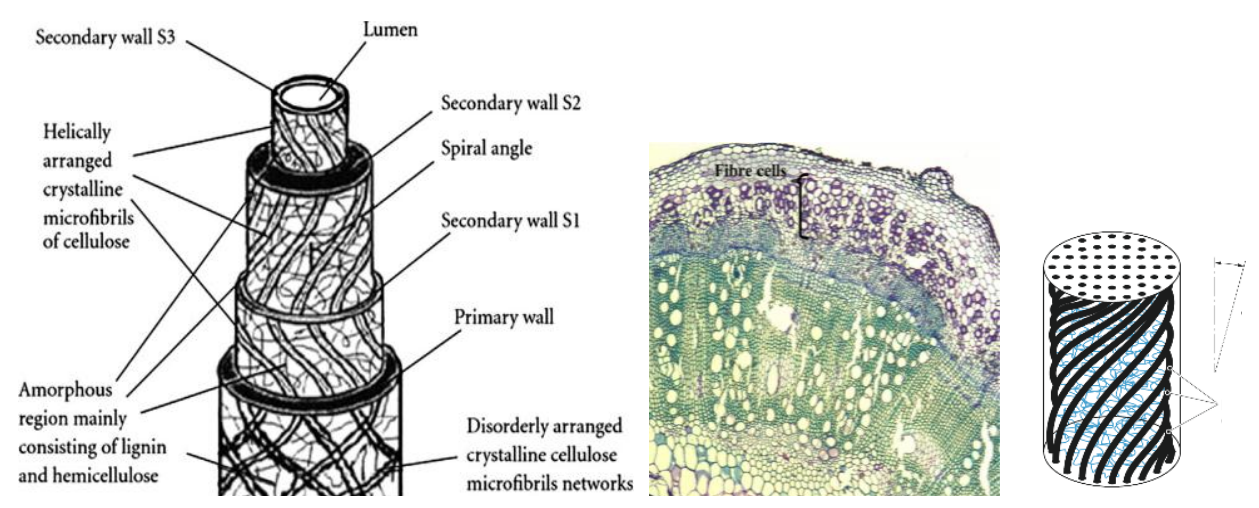


Figure 2. Microstructure and cross section of a stinging Nettle stem (x5) (Baley 2013b; Di Virgiolio et al. 2015), illustration of the $\mathrm{Z}$ and $\mathrm{S}$ twist disposition (Bodros and Baley 2008) and of microfibril angle representation (Hearle 1963).

The length of Nettle and Ramie fibers can vary widely depending on the species. It also depends on the growing conditions and the harvesting methods as this influence the final quality of the fiber. Variability in mechanical properties also seems to be more important for short fibers than for longer ones (Torres et al. 2017). According to Kumar and Das (2019), Nettle fibers can reach length of 1 or 2 meters depending on the species even though they are generally cut into small pieces of 1 to $10 \mathrm{~cm}$ to be used in composite.

\section{Chemical fibers composition; Nettle and Ramie specifications}

Like other natural materials, Nettle and Ramie fibers are mainly composed of cellulose, hemicellulose, lignin and pectin. The composition varies all along the life of the plant depending on the specie first, but also on the growing conditions. Usually, young plants are more flexible than older ones because they contain less cellulose and less lignin.

The determination of the compounds of a lignocellulosic material can be achieved by various methods; we can mention for instance the methods of Van Soest, Prosky, Uppsala, Selvendran and Godin for non-starch polysaccharides (Godin et al. 2011). The Van Soest method (Van Soest 1985) is the one with the best compromise between the data obtained and the analysis time. It consists, using neutral and acid detergents, in fractionating the lignocellulosic biomass fibers by successive chemical extractions and quantifying the dry insoluble fibers recovered after filtration by gravimetry. It allows the extraction of non-structural carbohydrates, pectins, gums, mucilages, tannins soluble at neutral $\mathrm{pH}$, lipids, proteins soluble in neutral detergent and some ashes.

Cellulose is one of the stiffest natural material with a theoretical elastic modulus of 135GPa when fully crystalline (CARMA 2006; Gurunathan et al. 2015), but this is rarely the case as pure cellulose is often mixed with other components leading to tensile properties far below this potential (around 40GPa) according to Bledzki and Gassan (1999); it is made of crystalline area (around 80\%) and amorphous area (20\%) according to Bouzouita (2011). This increase of cellulose content is visible when looking at a cross section of the fiber, the cell walls are getting thicker and the size of the lumen decreases. Cellulose is a natural linear polymer of $\beta$-D-glucopyranose (1-4) with a polymerization degree comprised between 7000 and 15000 depending on species. The many hydroxyl groups it contains are responsible for the capacity to reach high crystallinity ratio as these chemical bonds maintain the chains together. Tensile modulus would be eight times smaller without these chemical bonds (Summerscales et al. 2010b). Cellulosic chains are assembled in micro-fibrils having diameter comprised between 2 and 20nm (Do Thi 2011) and rolled around the longitudinal axis of the fiber with an angle varying from one species to another and determining the final stiffness of the fiber (Bergfjord and Holst 2010). Each micro-fibrils contains around 40 molecules and a diameter of $3.5 \mathrm{~nm}$, micro-fibrils are grouped in fibrillar bundles measuring $25 \mathrm{~nm}$ in diameter and $100 \mathrm{~nm}$ to $40 \mu \mathrm{m}$ in length (Summerscales et al. 2010b). The high content of hydroxyl group is also responsible for the hydrophilic behavior of the fiber. However, moisture acts as a plasticizer on cellulose by replacing chemical bonds between chains, this can result in $30 \%$ loss in tensile strength (Do Thi 2011) and reduction by 2 to 4 times of the tensile modulus. 
Cellulose is highly responsible for final mechanical properties, but it is not the only parameter to take into account; for instance, cotton fibers contain $92 \%$ cellulose and they bring poor mechanical reinforcement (Gourier 2016). Cellulose degrades very quickly around $350^{\circ} \mathrm{C}$, as the main component of natural fiber, it must be kept as pure as possible, but fabrication processes generally need temperature around $200^{\circ} \mathrm{C}$ especially with thermoplastics. Therefore, it is important to be aware of this fact when dealing with biofibers (Summerscales et al. 2010b).

Hemicellulose is another essential constituent of natural fibers; it generally surrounds micro-fibrils chains (Figure 3). Hemicellulose has a non-crystalline structure and a polymerization degree comprised between 50 and 300 with an important degree of chain branching (Beg 2008; Bledzki and Gassan 1999; Kritschewsky 1996). Hemicellulose increases stiffness and flexibility of cellular walls through the formation of covalent bonds, the elastic modulus of hemicellulose is around 8Gpa (Gurunathan et al. 2015). It is hydrophilic and easily hydrolysable in acids. Different kinds of hemicellulose exist depending on the specie, the growing conditions, the position inside the plant, or even its age (Do Thi 2011).

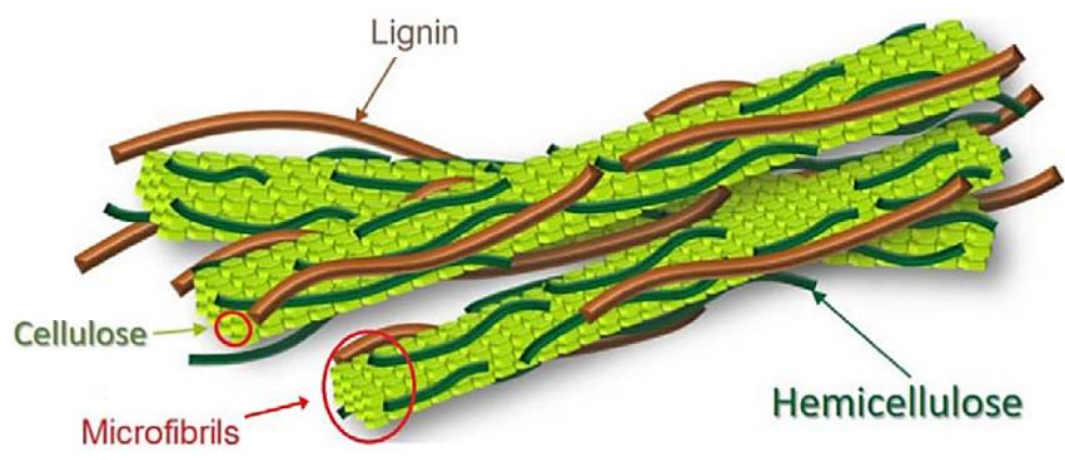

Figure 3. Diagram showing the structural arrangement of lignin, hemicellulose and cellulose microfibrils among each other (Jensen et al. 2017).

The third most important chemical constituent of natural fiber is the lignin. It is one of the most available polymers on earth after polysaccharides. Lignin is responsible for the stiffness of cellular walls and helps to protect the plant from pathogenic organisms. Lignin also acts as a barrier against water, reducing infiltration through the cellular wall. Mechanical properties of lignin are far from those of cellulose with only 4GPa for the elastic modulus, but it acts like a sleeve around micro-fibrils and therefore increases their compression strength. Lignin is considered as a thermoplastic polymer with a glass transition around $90^{\circ} \mathrm{C}$ and a melting temperature of $170^{\circ} \mathrm{C}$ (Gurunathan et al. 2015).

Then come the fourth constituent of natural fibers: pectin. Due to the presence of a large number of carboxylic acid on this substituted polygalacturonic complex polysaccharide pectin is the most hydrophilic constituent (Bouzouita 2011). It acts like cement in the cells around the fibers (Murariu and Dubois 2016).

Table 3. Chemical composition and microfibril angle of natural fibers (Du et al. 2015; Gurunathan et al. 2015).

\begin{tabular}{lclllll}
\hline Fiber & $\begin{array}{l}\text { Cellulose } \\
(\mathrm{wt} \%)\end{array}$ & $\begin{array}{l}\text { Lignin } \\
(\mathrm{wt} \%)\end{array}$ & $\begin{array}{l}\text { Hemicellulose } \\
(\mathrm{wt} \%)\end{array}$ & $\begin{array}{l}\text { Pectin } \\
(\mathrm{wt} \%)\end{array}$ & $\begin{array}{l}\text { Wax } \\
(\mathrm{wt} \%)\end{array}$ & $\begin{array}{l}\text { Microfibril } \\
\text { angle }(\mathrm{deg})\end{array}$ \\
\hline Jute & $61-71.5$ & $12-13$ & $13.6-20.4$ & 0.2 & 0.5 & 8.0
\end{tabular}




\begin{tabular}{lllllll} 
Flax & 71 & 2.2 & $18.6-20.6$ & 2.3 & 1.7 & 10.0 \\
Hemp & $70.2-74.4$ & $3.7-5.7$ & $17.9-22.4$ & 0.9 & 0.8 & 6.2 \\
Ramie & $68.2-76.2$ & $0.6-0.7$ & $13.1-16.7$ & 1.9 & 0.3 & 7.5 \\
Kenaf & $31-39$ & $15-19$ & 21.5 & - & - & - \\
Sisal & $67-78$ & $8.0-11.0$ & $10.0-14.2$ & 10.0 & 20. & 20.0 \\
Palm & $70-82$ & $5-12$ & - & - & - & 14.0 \\
Henequen & 77.6 & 13.1 & $4-8$ & - & - & - \\
Cotton & 82.7 & - & 5.7 & - & 0.6 & - \\
Coir & $36-43$ & $41-45$ & $0.15-0.25$ & $3-4$ & - & $41-45$ \\
\hline
\end{tabular}

Due to the relatively high content of hydroxyl group, natural fibers are sensitive to relative humidity and generally contain around $5 \%$ to $15 \%$ of moisture (Barbulée 2015; CARMA 2006; Nabi and Jog 1999). This is actually a challenge when manufacturing composite materials because when water evaporates, it creates more porosities. The moisture also affects the size of the fiber and especially the diameter sometimes leading to embrittlement of the composite due to micro-cracks appearing with fiber swelling (Baley et al. 2005b). For instance, Ramie fibers have a water uptake comprised between $11 \%$ and $17 \%$ in a $65 \%$ relative humidity and $20^{\circ} \mathrm{C}$ environment. This causes a transversal swelling of $12 \%$ to $15 \%$ and a global swelling of 32\% (Dittender and GangaRao 2012; Faruk 2012; Ho et al. 2012; Industrial Applications 2010).

\section{Mechanical properties of fibers and Nettle fibers}

Mechanical properties of natural fibers vary greatly from specie to specie and even from plant to plant in the same culture (Bodros and Baley 2008; Bouzouita 2011; Frollini 2000). Mechanical properties depend on various parameters such as chemical and physical properties, structure, cellulose content, micro-fibrils angle, cross section dimensions, polymerization degree and many others, even the nature of the testing equipment has been reported to affects the measured properties (Bledzki and Gassan 1999). Usually, for a given cellulose content, the higher the micro-fibril angle, the higher the elongation at break. Conversely, the lower the angle, the higher the stiffness and strength. The tensile behavior also varies according to the angle of the microfibrils and, therefore, three typical behaviors are identified for natural fiber (Figure 4).

(a)

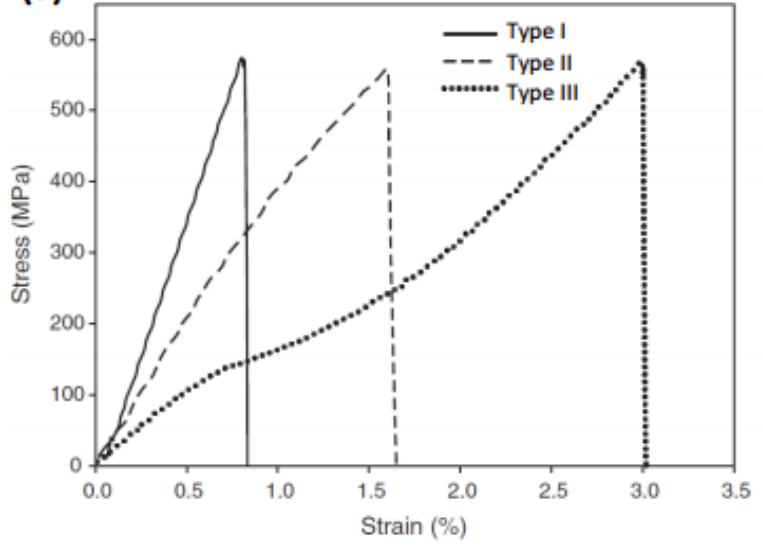

(b)

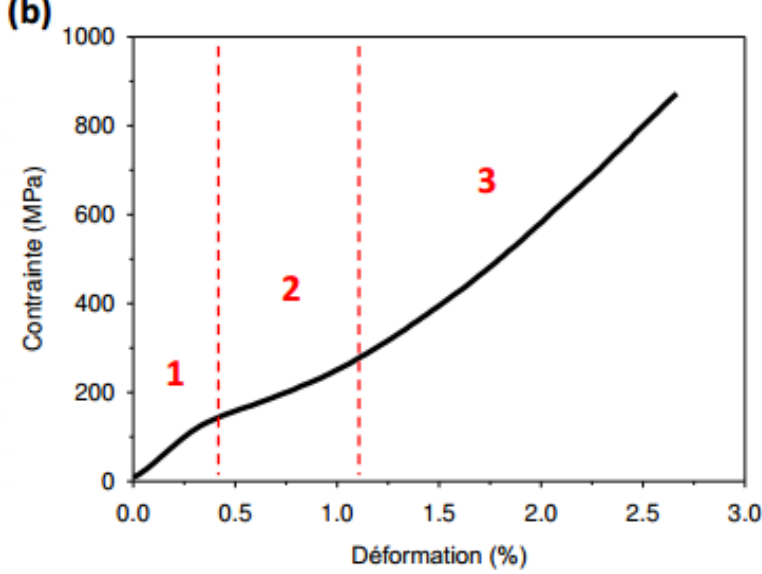


Figure 4. (a), illustration of tensile Type behavior for natural fiber; (b), detail of different zones for a Type III (Gourier 2016).

The Type I corresponds to an elastic behavior which happens with fibers having low micro-fibrillar angles. Type II corresponds to fibers with a small micro-fibrillar angle, thus causing a small variation of the tensile modulus. Finally, the Type III corresponds to fibers with an important micro-fibrillar angle. During traction, there is an elastic behavior first, then, the increasing tension creates shear in the secondary wall between cellulose micro-fibrils and hemicellulose leading to failure of the hydrogen bonds and to the stick-slip mechanism as bonds reform and fail again and again. Finally, once the fibers are aligned, there is once again an elastic behavior (Gourier 2016). It seems that this kind of behavior (Type III) occurs more frequently for fiber with higher moisture ratio due to loss of shear strength of hemicellulose and pectin.

According to Bodros and Baley (2008), the behavior of Nettle fiber under tension is found to be linear and elastic on the contrary to flax which it is considered as very lightly viscoelastic in Davies and Bruce (1998). In addition, Nettle fibers have a weak breakage with a low elongation at break as explained in Davies and Bruce (1998). At a larger scale, Eichhorn et al. (2001) have found that natural cellulose fibers have a linear behavior while regenerated amorphous cellulose (i.e. man-made) fibers have a non-linear behavior. Davies et al. also found that Nettle fibers extracted from non-retted plants have a higher damage rate than the ones from retted plant (Davies and Bruce 1998).

Comparative tables of mechanical properties of these different fibers indicates that Nettle fiber can reach an elastic modulus close to the one of glass fiber with $87 \mathrm{GPa}$ whereas hemp, flax and Ramie respectively reach 45, 70 and 130GPa (Baley 2013c). Concerning tensile strength, Nettle fibers reach $1600 \mathrm{MPa}$ for some of them while Ramie, hemp and flax respectively reach 500, 1500 and 800MPa. Elongation at break vary between 0.9 and $2.5 \%$ depending on the study (Gourier 2016). That is equivalent to Elongation at break of hemp but is lower than the one of flax and Ramie (Bodros and Baley 2008). However, the density of Nettle fibers is one of the highest among natural fibers as it reaches $1.45 \mathrm{~g} / \mathrm{cm}^{3}$ while it is only $1.38 \mathrm{~g} / \mathrm{cm}^{3}$ for flax, $1.35 \mathrm{~g} / \mathrm{cm}^{3}$ for hemp and $1.5 \mathrm{~g} / \mathrm{cm}^{3}$ for Ramie. Considering specific properties (according to the fiber density), Nettle and Ramie fibers remain attractive for mechanical use. Similarly, ramie fibers have interesting mechanical properties, especially in tension, this explains its widespread use and the abundant literature about it. Other benefits such as easy cultivation, low water consumption, and potential use of other parts of the plant for food or medicine make the culture of Nettle and Ramie really attractive.

Table 4. Mechanical characteristics of Nettle and Ramie fibers.

\begin{tabular}{llllllll}
\hline Fiber & $\begin{array}{l}\text { Density } \\
\left(\mathrm{g} . \mathrm{cm}^{-3}\right)\end{array}$ & $\begin{array}{l}\text { Diameter } \\
(\mu \mathrm{m})\end{array}$ & $\begin{array}{l}\text { Length } \\
(\mathrm{mm})\end{array}$ & $\begin{array}{l}\text { Young } \\
\text { modulus } \\
(\mathrm{GPa})\end{array}$ & $\begin{array}{l}\text { Tensile } \\
\text { strength } \\
(\mathrm{MPa})\end{array}$ & $\begin{array}{l}\text { Elongation } \\
\text { at break }\end{array}$ & Ref. \\
\hline Ramie & 1.5 & $20-30$ & - & - & - & - & Choi 2012 \\
& 1.5 & - & - & 23 & 450 & - & Xu 2012 \\
& 1.5 & $16-126$ & $40-250$ & 44 & 550 & 2 & CARMA 2006 \\
& 1.56 & - & - & $61.4-128$ & $400-938$ & $1.2-3.8$ & Dittender 2012 \\
& - & - & 10 & - & $850-900$ & - & Yu 2010 \\
& - & $4.6-126$ & $40-260$ & $5-128$ & $290-1060$ & $0.2-6$ & Industrial 2010 \\
& 1.5 & - & - & $42-86$ & $266-630$ & 1.6 & Kalia 2009 \\
& 1.51 & 34 & - & $24.5-65$ & $560-900$ & 2.5 & Bodros 2008 \\
& $1-1.55$ & $20-80$ & - & $24.5-128$ & $400-1000$ & $1.2-4.0$ & Sanjay 2018 \\
& $1.5-1.6$ & 49 & - & $61.4-128$ & $400-938$ & $1.2-3.8$ & Koronis 2013 \\
& $1.4-1.5$ & $20-80$ & $900-$ & $38-44$ & $500-680$ & - & Dicker 2014 \\
\hline
\end{tabular}




\begin{tabular}{|c|c|c|c|c|c|c|c|}
\hline \multirow{3}{*}{$\begin{array}{l}\text { Nettle } \\
(\mathrm{NaOH})\end{array}$} & \multirow[b]{2}{*}{ - } & \multirow[b]{2}{*}{-} & \multicolumn{5}{|l|}{1200} \\
\hline & & & $\begin{array}{l}21.6 \pm 0 . \\
8\end{array}$ & $479.9 \pm 17$ & $2.60 \pm 0.1$ & - & Du 2015 \\
\hline & - & - & $55 \pm 1$ & $20.2 \pm 1$ & $626.2 \pm 28$ & $4.4 \pm 0.1$ & Du 2015 \\
\hline \multirow{8}{*}{$(\mathrm{NaOH})$} & - & $20 \pm 2$ & - & $87 \pm 28$ & $1594 \pm 640$ & $\begin{array}{l}2.11 \pm 0 . \\
83\end{array}$ & Bodros 2008 \\
\hline & 1.327 & - & $55 \pm 1$ & - & 468.69 & 2.42 & Kumar 2018d \\
\hline & 1.160 & $72.58 \pm 20.7$ & - & - & - & 4.3 & Thilgavathi19 \\
\hline & 1.452 & & - & - & - & - & Bajpai 2015 \\
\hline & 1.378 & 53.64 & 600 & - & - & 1.81 & Raj 2020 \\
\hline & - & $25.7 \pm 0.2$ & - & $26.451 \pm 14.4$ & $930 \pm 500$ & $3.6 \pm 1$ & Fischer 2012 \\
\hline & - & - & - & 38 & 650 & 1.7 & Sanjay 2018 \\
\hline & - & - & - & $25.5 \pm 6.8$ & $368 \pm 195$ & $\begin{array}{l}1.65 \pm \\
0.92\end{array}$ & Davies 1998 \\
\hline
\end{tabular}

\section{Other specification of Nettle/Ramie fibers}

\section{Moisture influence on fibers comportment}

Natural fibers are polar (hydrophilic) which explains why they absorb moisture. According to Verma and Senal (2019), moisture absorption increases with fiber ratio. In fact, increasing the fiber loading contributes to increase connections between fibers in the matrix therefore leading to water diffusion while percolation with low fiber loaded composites. This character is confirmed by Peijs and al. (1998) reporting that cellulose and hemicellulose are responsible for moisture absorption leading to fiber swelling and degradation of the mechanical properties. Three mechanisms are involved, the first one consists in the diffusion of water molecules in the voids between the fibers following a Fickian law. The second and the third mechanism are capillarity and diffusion of water inside the fiber (Sanjay 2018).

\section{Oil absorption}

Most bast fibers (plant stem) are adapted to oil sorption because of their hollowness and their rough surfaces, which create a capillary action (Thilgavathi and Karan 2019). This is even more the case when fibers are submitted to alkaline treatments, which increase their roughness. The oil sorption efficiency of fibers depends on the sorption capacity but also on the retention capacities of the fibers. This is tightly linked with the porosity and the pore's diameter. It has been found that Nettle fabric exhibits sorption capacity up to $56 \mathrm{~g} / \mathrm{g}$ for high density oil and up to $23.9 \mathrm{~g} / \mathrm{g}$ for diesel oil.

\section{Sound absorption}

For Raj et al. (2020), Nettle performs better than most natural fibers especially in low frequencies beyond $500 \mathrm{~Hz}$ with an NRC greater than 0.7 . This might be due to the larger diameter of the fiber. Moreover, the rough surface of the fiber may also help to enhance fiber interlocking resulting in higher density.

\section{Biocomposite Polylactic-acid/Nettle}


PolyLactic Acid (PLA) is a relatively new polymer that came onto the market in 2002 (Murariu and Dubois 2016) with the main advantage of being fully biobased and therefore biodegradable. There are very few polymers in this category among which one can also find thermos plastic starch (TPS), starch blends, polyhydroxyalcanoate (PHA), PLA/PHA blends, cellulose acetate and regenerated cellulose (Faruk et al. 2012). PLA is an important part of the growing biopolymer market, with global production increasing fourfold between 2011 and 2020 from 200kt/year to 800kt/year (Murariu and Dubois 2016). It can be synthetized through different processes (Figure 5). The two main processes are the Ring-Opening Polymerization (ROP) and the polycondensation (Sudamrao Getme and Patel 2020), as explained in Figure 5. Usually, it is produced from corn starch, potato starch or sugar fermentation which makes it available in large quantities. Due to its availability and good mechanical properties, PLA is a bio counterpart to PE and PP. Due to the chiral character of lactic acid, still under development, are different types of PLA with different final properties (PLLA, PLA, PDLA, PDLLA) depending on the percentage of $L$ and D monomer. PLA is also available under different forms and colors as it is also mainly used in the world of 3D printing (CisnerosLopez 2020). The common form of PLA are powder, fibers, pellets, films and filaments. As a crystalline polymer, mechanical properties of PLA can be modulated with its crystallinity rate. In most cases, PLA has a tensile modulus comprised between 0.5 and $3.5 \mathrm{GPa}$, a tensile strength up to $65 \mathrm{MPa}$ and an elongation at break around 2 to $6 \%$ depending on the crystallinity (Iron 2020; Notta-Cuvuer et al. 2018; Söderguard and Mickael 2002; Xu et al. 2012). However, PLA is a relatively weak polymer as it does not support big plastic strain (Murariu and Dubois 2016).

PLA is thermoplastic, unlike the usual epoxy resin used in composite materials, which is a thermoset, so it can be reformed simply by heating. This is due to its internal structure made of long linear chains of polymer that are entangled during cooling (Aucher 2009). As a thermoplastic polymer, PLA can have different degrees of crystallinity, which directly affects its mechanical and thermal properties (Figure 5). The higher the crystallinity, the greater the risk of thermal shrinkage, but the dimensional stability remains very interesting (Aucher 2009). The crystallinity degree is controlled by the cooling rate, amorphous thermoplastics can be obtained through quick cooling while crystalline thermoplastic can reach up to $80 \%$ of crystallinity when cooled slowly. Therefore, depending on the targeted properties, crystallinity has to be assessed with better creep and impact resistance for amorphous thermoplastics whereas crystalline thermoplastics perform better in tension and usual solicitations (Aucher 2009; Nguyen 2016c). However, the crystallization rate of PLA is one of the lowest among thermoplastics, thus limiting its use in high-performance applications. Nevertheless, it is possible to artificially increase the crystallization of PLA by adding talc, which leads to an increase in stiffness and heat resistance, better dimensional stability as well as a reduction in production costs due to the shorter time needed for crystallization (Chen 2005). 

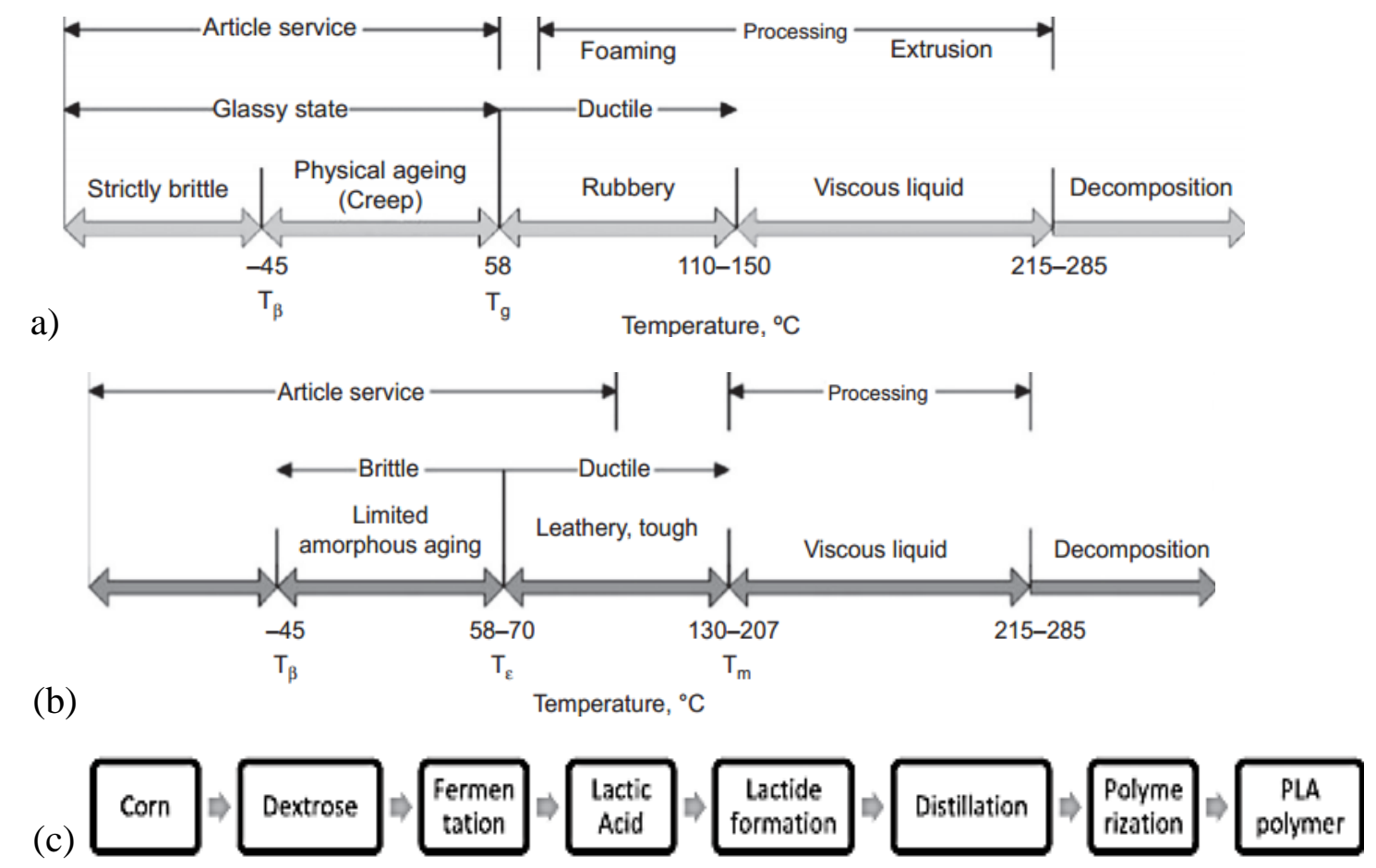

Figure 5. Metastable states of amorphous PLA (a) and semi crystalline (b) PLA, (Loureiro and Esteves 2019), (c) Synthetization of PLA (Sudamrao Getme and Patel 2020).

The PLA is also sensitive to moisture, which acts like a plasticizer, thus reducing tensile properties while increasing elongation at break due to hydrolysis and breakage of polymer chains (Penu and Helou 2017). Chemical plasticizers are also commonly added into PLA during fabrication to increase its ductility, especially since low quantities improve by 20 to 45 times its natural ductility (Notta-Cuvier et al. 2018). It is also common to add nanofillers inside PLA to increase nucleation effects and improve its resilience, but at the expense of stress strength (Baley 2013c). However, PLA is also a polymer with relatively low working temperatures. The melting temperature varies between $180^{\circ} \mathrm{C}$ and $210^{\circ} \mathrm{C}$ while the glass transition temperature is closer to $60^{\circ} \mathrm{C}$. Alternative PLA are therefore in development and show interesting properties such as higher melting temperature around 220 or $230^{\circ} \mathrm{C}$ (Murariu and Dubois 2016). Therefore, working with natural fibers requires caution to avoid thermal degradation. It is also necessary to check that working temperature of the final product is below the glass transition, especially in case of structural application (Penu and Helou 2017). However, being a polar material (Yan and Kortschot 2015), PLA tends to bind more readily to natural fibers than do typical thermoplastics.

\section{Properties of the PLA/Nettle composite}

The quality, and therefore, the performances of a composite material greatly depend on parameters such as fiber length, disposition, ratio, etc. (Nabi Saheb and Jog 1999; Beg 2008). In addition, in order to obtain a composite with good mechanical performance, the fibers and the matrix must have, as much as possible, the following criteria:

- For the fiber: high elasticity modulus, high ultimate strength, low dispersion between fibers, stability during handling and manufacturing, uniform diameter. 
- For the matrix: fiber binding efficiently (protecting them from exterior damages), stress transfer by adhesion, ability to disperse and impregnate the fiber, being chemically and thermally compatible with the fiber.

\section{Mechanical behavior of the PLA/Nettle composite}

The purpose behind the creation of composite materials is to create a new material whose properties cannot be reached with its homogeneous constituents alone. Therefore, adding fibers in a thermoplastic or thermoset matrix improves its mechanical properties with fiber more adapted to bear the load while matrix maintain cohesion and bear shearing and compression (Bacquaert 2013; Shahzad 2017). As the composition of the composite is adjustable, it is possible to create a specific composite to reach all the mechanical properties comprised between pure matrix and pure fibers.

Once a certain fiber fraction is reached, mechanical properties tends to decrease rapidly due to low impregnation of the fiber and higher porosity ratio. According to Choi and Lee (2012), the addition of $30 \%$ in mass of fiber to a PLA matrix causes a 50\% increase in the impact strength when compared to neat PLA. Among existing studies, major results are presented in Table 5.

Table 5. Comparative table of the mechanical properties of Nettle and Ramie composites obtained in different studies (*corresponds to volumic ratio).

\begin{tabular}{|c|c|c|c|c|c|c|c|}
\hline $\begin{array}{c}\text { Compo } \\
\text { site }\end{array}$ & $\begin{array}{l}\text { Fibers } \\
\text { Length }\end{array}$ & Treatment & $\begin{array}{c}\text { Fiber prop. } \\
(\text { wt } \%)\end{array}$ & $\begin{array}{l}\text { Young } \\
\text { modulus } \\
(\mathrm{GPa})\end{array}$ & $\begin{array}{c}\text { Tensile } \\
\text { strength } \\
\text { (MPa) }\end{array}$ & $\begin{array}{c}\text { Elongation } \\
\text { at break } \\
(\%)\end{array}$ & Ref. \\
\hline \multirow{17}{*}{$\begin{array}{l}\text { Nettle/ } \\
\text { PLA }\end{array}$} & \multirow{6}{*}{$\begin{array}{l}55 \mathrm{~mm} \\
\pm 1 \mathrm{~mm}\end{array}$} & \multirow{6}{*}{$\mathrm{NaOH}$} & 0 & $2.21 \pm 0.07$ & $2.21 \pm 1.03$ & $0.83 \pm 0.21$ & \multirow{6}{*}{ Kumar 2016b } \\
\hline & & & 10 & $2.37 \pm 0.05$ & $15.54 \pm 0.45$ & $1.42 \pm 0.06$ & \\
\hline & & & 25 & $3.11 \pm 0.05$ & $36.70 \pm 1.3$ & $1.80 \pm 0.08$ & \\
\hline & & & 50 & $3.34 \pm 0.04$ & $50.82 \pm 0.82$ & $2.45 \pm 0.10$ & \\
\hline & & & 75 & $2.33 \pm 0.06$ & $27.04 \pm 1.17$ & $1.80 \pm 0.09$ & \\
\hline & & & 90 & $2.19 \pm 0.04$ & $15.92 \pm 0.45$ & $1.11 \pm 0.06$ & \\
\hline & \multirow{7}{*}{$\begin{array}{l}55 \mathrm{~mm} \\
\pm 1 \mathrm{~mm}\end{array}$} & \multirow{7}{*}{$\mathrm{NaOH}$} & 10 & - & 15.31 & 1.5 & \multirow{7}{*}{ Kumar 2018d } \\
\hline & & & 25 & - & 36.23 & 3.1 & \\
\hline & & & 30 & - & 43.46 & 2.83 & \\
\hline & & & 35 & - & 45.05 & 2.94 & \\
\hline & & & 40 & - & 51.61 & 2.97 & \\
\hline & & & 45 & - & 53.77 & 3.29 & \\
\hline & & & 50 & - & 50.94 & 1.8 & \\
\hline & \multirow{4}{*}{ Fabric } & - & 0 & $-3.5 \pm 0.1$ & $51.98 \pm 1.18$ & - & \multirow{4}{*}{ Fischer 2012} \\
\hline & & - & 20 & $\sim 4.7 \pm 0.2$ & $\sim 45 \pm 4$ & $1.2 \pm 1.8$ & \\
\hline & & - & 30 & $\sim 5.6 \pm 0.4$ & $\sim 58 \pm 3$ & $1.5 \pm 1.8$ & \\
\hline & & - & 40 & $\sim 4.8 \pm 0.7$ & $\sim 40 \pm 11$ & $1.3 \pm 1.8$ & \\
\hline Ramie & - & - & 30 & $\sim 3.4 \pm 0.2$ & $\sim 72 \pm 6$ & - & \multirow{4}{*}{ Choi 2012} \\
\hline \multirow{7}{*}{ /PLA } & - & Alkali & 30 & $\sim 2.8 \pm 0.1$ & $\sim 46 \pm 2$ & - & \\
\hline & - & Alkali+S & 30 & $\sim 2.6 \pm 0.1$ & $\sim 27 \pm 2.5$ & - & \\
\hline & . & Peroxide & 30 & $\sim 2.3 \pm 0.2$ & $\sim 33 \pm 5$ & - & \\
\hline & \multirow{3}{*}{$10 \mathrm{~mm}$} & & 30 & $4.3 \pm 0.2$ & $59 \pm 0.8$ & $4.1 \pm 0.3$ & \multirow{3}{*}{$\mathrm{Yu} 2014 \mathrm{~b}$} \\
\hline & & $3 \% \mathrm{MA}$ & 30 & $4.4 \pm 0.1$ & $64.3 \pm 1.2$ & $4.4 \pm 0.3$ & \\
\hline & & $5 \% \mathrm{MA}$ & 30 & $4.5 \pm 0.1$ & $61.7 \pm 0.9$ & $4.3 \pm 0.1$ & \\
\hline & $10 \mathrm{~mm}$ & - & $0 *$ & & 45.2 & $1.2 \pm 0.2$ & Yu 2009a \\
\hline
\end{tabular}




\begin{tabular}{|c|c|c|c|c|c|c|c|}
\hline & & $\begin{array}{l}- \\
- \\
- \\
- \\
-\end{array}$ & $\begin{array}{l}10^{*} \\
20^{*} \\
30^{*} \\
40^{*} \\
50^{*}\end{array}$ & & $\begin{array}{c}49.8 \pm 2 \\
50.9 \pm 2 \\
52.5 \pm 2 \\
46 \pm 2 \\
44.8 \pm 1\end{array}$ & $\begin{array}{c}2.2 \\
3.5 \pm 0.2 \\
3.1 \pm 0.2 \\
2.5 \pm 0.2 \\
2.2 \pm 0.2\end{array}$ & \\
\hline & $10 \mathrm{~mm}$ & $\begin{array}{l}\text { Alkali/ } \\
\text { Silane }\end{array}$ & $\begin{array}{c}30 \\
30 \text { (Alkali) } \\
30 \text { (Silane1) } \\
30 \text { (Silane2) }\end{array}$ & $\begin{array}{l}3.2 \pm 0.2 \\
4.8 \pm 0.2 \\
4.1 \pm 0.2 \\
3.6 \pm 0.1\end{array}$ & $\begin{array}{l}52.5 \pm 0.8 \\
66.8 \pm 1.7 \\
59.3 \pm 1.2 \\
64.2 \pm 0.2\end{array}$ & - & Yu 2010c \\
\hline & $\begin{array}{l}\text { Short } \\
\text { fibers }\end{array}$ & - & $\begin{array}{c}0 \\
10 \\
20 \\
30 \\
\end{array}$ & $\begin{array}{l}1.47 \pm 0.02 \\
1.92 \pm 0.03 \\
2.47 \pm 0.04 \\
2.98 \pm 0.05\end{array}$ & $\begin{array}{l}65.6 \pm 1.4 \\
70.0 \pm 1.9 \\
80.2 \pm 2.3 \\
91.3 \pm 2.8 \\
\end{array}$ & $\begin{array}{l}7.3 \pm 0.5 \\
6.4 \pm 0.2 \\
5.9 \pm 0.3 \\
5.7 \pm 0.1 \\
\end{array}$ & Xu 2012 \\
\hline $\begin{array}{c}\text { Nettle/ } \\
\text { PP }\end{array}$ & $\begin{array}{c}- \\
- \\
\text { Fabric } \\
\end{array}$ & $\begin{array}{l}- \\
- \\
-\end{array}$ & $\begin{array}{c}0 \\
30 \\
-\end{array}$ & $\begin{array}{c}\sim 1.8 \pm 0.2 \\
\sim 1.3 \pm 0.3 \\
-\end{array}$ & $\begin{array}{c}\sim 14 \pm 3 \\
\sim 12 \pm 3 \\
32.56\end{array}$ & $\begin{array}{l}- \\
- \\
-\end{array}$ & $\begin{array}{l}\text { Gourier } 2016 \\
\text { Pokhriyal } 2018\end{array}$ \\
\hline $\begin{array}{l}\text { Nettle/ } \\
\text { PS }\end{array}$ & Fabric & $\begin{array}{l}- \\
- \\
- \\
- \\
-\end{array}$ & $\begin{array}{c}0 \\
5 \\
10 \\
15 \\
20\end{array}$ & $\begin{array}{l}- \\
- \\
- \\
- \\
-\end{array}$ & $\begin{array}{c}\sim 17.5 \pm 0.49 \\
\sim 19.8 \pm 0.67 \\
\sim 23.22 \pm 0.85 \\
\sim 30.69 \pm 0.57 \\
\sim 29.08 \pm 0.81\end{array}$ & $\begin{array}{l}- \\
- \\
- \\
- \\
-\end{array}$ & Baley 2002a \\
\hline
\end{tabular}

Table 5. Comparative table of the mechanical properties of Nettle and Ramie composites obtained in different studies (*corresponds to volumic ratio).

\section{Thermal behavior of the PLA/Nettle composite}

Adding fibers into a thermoplastic also modifies the thermal properties of the composite. Therefore, $\mathrm{Yu}$ and al. (2014) reports that the glass transition as well as the molding temperature increase when Ramie fibers are added into the matrix of PLA. The Vicat softening temperature also increases significantly going from $60^{\circ} \mathrm{C}$ for neat PLA up to $103^{\circ} \mathrm{C}$ for the composite loaded with $30 \%$ of Ramie. The addition of fibers also reduces the thermal expansion of the composite (Fischer, Werwein and Graupner 2012).

Another limitation of natural fiber is their sensibility to temperature, depending on the study, it is generally assumed that natural fibers are damaged when processing temperatures are higher than $200^{\circ} \mathrm{C}$ to $240^{\circ} \mathrm{C}$ (Nabi Saheb and Jog 1999; Nguyen 1981a, 1981b, 2016c) obviously depending on exposure time. This major constraint reduces the choice for thermoplastics and especially for high performances thermoplastics as PEEK, which have processing temperature over $300^{\circ} \mathrm{C}$. Raj et al. (2020) report that thermogravimetric analysis (TGA) conducted on Nettle fibers indicates that mass loss occurs from $35^{\circ} \mathrm{C}$, this initial mass loss is due to moisture evaporation. It reaches about $5 \%$ at $250^{\circ} \mathrm{C}$ with a loss of mass up to $80 \%$ between 300 and $380^{\circ} \mathrm{C}$. The mass of the fiber remains more or less constant until $300^{\circ} \mathrm{C}$ where cellulose, hemicellulose, and other components start to degrade. Kumar and Das (2019) also deduced from TGA analysis that increasing the fiber content in a PLA/Nettle composite leads to increased thermal stability.

Temperature can also have a positive effect on the mechanical properties of composite materials with a thermoplastic resin. For instance, maintaining a Ramie/PLA composite at $115^{\circ} \mathrm{C}$ for one hour and letting it cool down after increases the tensile strength and the tensile stress, while reducing the elongation at break as compared to a non-treated composite (Chen 
2014a). This difference is explained by the higher crystallinity of PLA achieved during the heat curing time.

The DMA test is used to characterize the viscoelastic behavior of the composite. This test allows to find the glass transition temperature, melting temperature, storage modulus, loss modulus or the damping factor of the composite. These parameters are different ways to evaluate the energy stored in a material. For instance, the highest storage modulus for a PLA/Nettle composite is obtained with an equal weight proportion (Kumar 2019), while the $10 / 90$ and the $75 / 25$ proportion give lower results. Moreover, the addition of $50 \%$ in fiber weight almost double the storage modulus, going from $2.427 \mathrm{GPa}$ for neat PLA up to $4.024 \mathrm{GPa}$ at $35^{\circ} \mathrm{C}$, but it has also been observed that the rate of the reduction in storage modulus as a function of temperature was decreasing with the increase in fiber ratio. A possible explanation is that the higher fiber ratio causes the reduction of the mobility of the polymer chains. The glass transition temperature is also clearly visible on DMA tests as it consists in a free molecular movement of the polymer chains and therefore corresponds to a brutal loss of storage modulus. The loss modulus, which is relative to the energy dissipated by the material at a certain temperature, also gives a good indication of the ability of the material to absorb energy. Again, it appears that equal weight composites give the highest energy absorption value for PLA/Nettle as well as other biocomposites such as PLA/Kenaf/APP and linen/HDPE (Kumar et al. 2019). The last parameter, called the damping factor or loss factor, corresponds to storage modulus divided by the loss modulus and is relative to the damping properties of the material. It also helps to find the precise value of the glass transition temperature. Still according to Hassler (2018), until 50wt\%, the glass transition temperature increases with the fiber rate while the damping factor decreases, then, when fiber ratio is above $50 \mathrm{wt} \%$, the glass transition temperature decreases and the damping factor increases.

According to Du et al. (2015), the addition of $30 \%$ of Ramie fiber to neat PLA decreased the cold crystallization temperature from $92.7^{\circ} \mathrm{C}$ to $88.4^{\circ} \mathrm{C}$, showing that Ramie fibers are an efficient nucleating agent.

Moreover, the thermal stability of a composite mainly depends on the matrix; therefore, it could be necessary to increase the crystallinity of the polymer or to add inclusions in order to increase the glass transition temperature (Yu et al. 2014).

\section{Fibers Length in PLA/Nettle composite}

Fiber length is a major parameter for composite materials. When long fibers are used, unidirectional composites offer the best tensile properties and create a highly orthotropic material. On the contrary, when short fibers are used, the final composite tends to be isotropic. Moreover, when fibers are reduced to an intermediate length, the mechanical behavior can vary greatly especially around a critical length, which depends on the fiber shape factor (length/diameter), but also on the interactions between the fibers and the matrix (Shahzad 2017). The critical shape factor is also defined as the minimum shape factor allowing to reach the maximum strength of the fiber. This last parameter is defined through experimentations such as the pullout test, the fragmentation test, the interfacial shear strength or the micro indentation test (Do Thi 2011). However, results vary greatly depending on the test method (Gourier 2016). The critical length is also interesting, it determines the global behavior of the composite. Below this value, the fiber is too short to support the load and the composite breaks, while above this critical length, the fibers are too long and sometimes break before the composite. It is interesting to know that longer fiber also affects moisture absorption due to higher diffusion (Thwe and Liao 2002). The fiber length is also determined by the fabrication process; for instance, if fibers are too long for injection molding, the intense shear caused by 
the screws will shorten the fiber (Gourier 2016). In the study of Bodros and Bailey (2008), $10-12 \mathrm{~mm}$ Ramie fiber give best results for tensile strength and modulus while $5-6 \mathrm{~mm}$ is better for impact properties. Therefore, depending on the exact species of the fibers and on the processing method, the resulting mechanical properties of a PLA/Nettle fibers can vary in quality and dimensions.

\section{Fibers arrangement in a PLA/Nettle composite}

In composite materials, the orientation of the fiber plays a major role in the mechanical properties, (Gehring 2013; Kumar 2018). The fibers are rigid while the matrix is generally ductile, making the composite a material capable of withstanding a high load in a desired direction. The fibers can be placed in the mold in different ways in a $1 \mathrm{D}, 2 \mathrm{D}$ or 3D pattern to form a fabric either unidirectionally (UD), bidirectionally or in 3D. The choice of this fiber arrangement is critical and determines the mechanical properties of the composite. Therefore, UD are preferred for pure traction while 2D mats or randomly orientated (3D) fibers performs better in flexibility with the lowest flexural modulus. 2D and 3D composites perform best in situation where load is applied under various solicitations (Khatkar et al. 2020). When fibers tend to be misaligned, with an off-axis angle from the direction of solicitation, the mechanical performances drop quickly. Instead, it is possible to use small pieces of randomly oriented fibers in the matrix. This creates a large-scale averaging effect that leads to an isotropic type material but with lower performances. The use of long fibers tends to generate agglomerates, resulting in poor impregnation, poor dispersion, and poor mechanical performance (Torres et al. 2017). Therefore, using intermediate length fibers seems to be interesting to harness both isotropic behavior and good averaged mechanical performances. But, due to the random orientation of most fibers, the final properties of this kind of material are difficult to predict using the traditional rules of mixture. Kumar et al. (2018), suggested an alternative formula to estimate tensile properties of the final composite using a probability density function to take into account the average inclination of the fiber.

Fiber can also be involved in sandwich structures especially for parts loaded under flexion. According to Chen, Lee et al. (2005), a simple 70/30 Ramie/PP composite gives better results than a Ramie/kenaf/Ramie sandwich composite (with 70/30 Ramie/PP and 70/30 kenaf/PP). In fact, the uniform structure performs better in tensile strength and modulus; it also has a higher flexural yielding stress and modulus than the sandwich structure.

\section{Fiber ratio in a PLA/Nettle composite}

$\mathrm{Yu}$ et al. (2009a) reported that the fiber ratio directly influences the mechanical properties of the composites. Therefore, tensile properties of the Ramie/PLA composite increase until 30\% fiber content and then decrease. In theory, increasing the fiber content tends to improve mechanical performances. In fact, due to incomplete bonding of the fiber with the matrix, the mechanical properties decrease over a certain fiber ratio ( $\mathrm{Lu}$ and al. 2006). Some studies (Xu et al. 2012) also find out that mechanical properties are not proportional to the fiber weight ratio and suggest a «cooperative effect » between the matrix and the fiber leading to a nonlinear improvement of the property when increasing regularly the fiber ratio. Low impregnation of the fiber when the fiber ratio is high may therefore be responsible for the loss of mechanical properties, but it is not the only reason for Nettle and also for kenaf fibers (a variety of hemp) (Kumar et al. 2019). In fact, increasing the fiber ratio beyond $50 \%$ by weight also means increasing fiber agglomeration and thus the generation of breakpoints. This ratio 
also corresponds to the highest impact strength and the lowest dry sand abrasion test. Consequently, there is not one ideal fiber ratio, as the ratio depends on the property to be maximized. Consequently, the ideal fiber ratio for maximizing tensile strength is lower than the one for maximizing tensile modulus because the modulus is less sensitive to local defect such as unwetted fibers. High fiber content also corresponds to low elongation at failure.

On the other hand, low fiber content is also responsible for higher risk of failure as the repartition of fiber creates stress concentrations. The minimum fiber volume ratio for lingocellulosic materials is $11 \%$ according to Shahzad (2017). It is therefore essential to test different compositions to find the one that gives the best results. Higher fiber content also leads to lower density due to higher porosity for PLA/Nettle.

\section{Fabrication methods of the PLA/Nettle composite}

There are several methods to produce composites with thermoplastics. The main ones are:

- Hot pressing (easier to realize but offers fewer possibilities) (Chevalier 1975; Wang et al. 2019).

- Injection molding (the most used for polymer; it requires a lot of force for injection creating a lot of residual shear stress, but it allows a lot of different shapes (Beg 2008).

- Compounding.

The processing method directly influences the final properties of the composite. Especially with thermoplastics such as PLA which is composed of amorphous and crystalline phases. Therefore, depending on the cooling rate after the injection or the hot pressing, the final properties may be partially changed depending on the crystallinity of the PLA (Aucher 2009). When injection molding is used, many parameters are also involved in the process. In (Xu et al. 2012), it is shown that high speed injection can help to keep a preferential orientation of the fiber leading to an anisotropic material. People need to be aware of this phenomenon, as it can have a significant influence on mechanical properties, such as improved tensile strength and elasticity modulus. For Nabi Saheb and Jog (1999) the use of mechanical processes usually causes fiber agglomeration due to their hydrophilic behavior and fiber-fiber interaction, but surface treatments can reduce this phenomenon.

\section{Effect of fibers treatments on the PLA/Nettle composite properties}

The final quality of a composite material highly depends on its ability to transfer the load between the matrix and the fibers, this transfer is mainly achieved through shear at the interface. As raw fibers are generally soft and contain unstructured materials such as pectin, different chemical treatments are applied to improve the interfacial adhesion either by adding a coating or by cleaning the 3 to $5 \mu \mathrm{m}$ fat-acid layer from the fiber (Shahzad 2017). For example, when Ramie fibers are treated with malic anhydride before being added to a PLA matrix (Yu et al. 2009a); SEM observation shows that after stressing the PLA matrix remains attached to the fibers, the material decomposes less easily.

\section{Fibers treatment with silane}

Treatment with silane (formula $\mathrm{SiH} 4$ ) generally causes an increase in fiber diameter which tends to create an interface between the fiber and the matrix. Thus, the silane acts as a coupling agent and generates a non-polar coating around the fiber to facilitate adhesion with the matrix. Most fibers are polar, while most matrices are non-polar, which most of the time 
results in poor adhesion between the fibers and the matrix and leads to poor quality composites. The silane treatment is considered as one of the best coupling agents for polymer/wood fiber composite. However, its effectiveness depends strongly on parameters such as the duration of hydrolysis, temperature, or $\mathrm{pH}$ (Jacob and Anandjiwala 2008). This treatment generally increases tensile strength and thermal stability of the fiber (Li et al. 2009). According to Dittenber and GangaRao (2012), when treated with silane (pretreated with alkaline treatment 1 hour in a $5 \% \mathrm{NaOH}$ mixture, dried $24 \mathrm{~h}$ at $60^{\circ}, 1$ hour in $1 \%$ silane mixture), the Ramie/PLA composite saw a $49.82 \%$ increase of its tensile strength when compared to the non-treated composite. Usually, silane treatments are applied using a 1 or $2 \%$ $\mathrm{SiH}_{4}$ concentration for $45 \mathrm{~min}$ to $3 \mathrm{~h}$ (Zhi et al. 2001). Interestingly, Kalia et al. (2009) reported that silane treatment increases the tensile strength of fibers while reducing the tensile modulus.

\section{Fibers treatment with Alkaline and Sodium hydroxide}

The alkali treatment is often used to clean the fiber from their impurities such as wax and pectin. In most cases, the consequence is a reduction of the diameter of the fiber. The alkaline treatment is also known for decreasing the content of hemicellulose and lignin of the fibers (Li et al. 2009). Due to the removal of individual constituents, the microfibrils are less dense and less stiff, but they also have more space to rearrange themselves in the tensile direction, which increases the tensile properties (Do Thi 2011). According to Kumar and Das (2016b), row fibers are-bumpy and irregular while the alkaline treated fibers $(0.5 \% \mathrm{NaOH} w / \mathrm{w}, 30 \mathrm{~min}$, $\left.30^{\circ} \mathrm{C}\right)$ are clean and straight. But when fibers are severely treated with alkali $(10 \% \mathrm{NaOH}, 6 \mathrm{~h})$, they seem to be damaged. X-ray diffractograms show an increase of the crystallinity index when fibers are treated with sodium hydroxide going from $66.81 \%$ for the row fibers to $68.60 \%$ for the treated ones and $68.45 \%$ for the severely treated ones. Nevertheless, as concluded in the study, alkaline treatment cannot be considered an effective way to increase crystallinity based on this result alone. Moreover, this study find that the alkali treatment yields the shape of the fiber and reduce the linear density from 24.6 (raw fiber) to 20.12 (severely treated fiber). But this treatment also has positive effects on the mechanical behavior of the fiber because the tensile strength and elongation at break increase while the tensile modulus hardly decreases, confirming that the alkaline treatment makes the fiber more elastic. Influence of different parameters involved in Alkali treatments such as alkali concentration, alkalization temperature, alkalization time, drying temperature and drying time have been investigated (Kumar and Das 2016a). Best results for elongation at break are obtained for high alkaline concentration, low drying temperature, and long drying time independently from alkalization time and temperature. For example, the highest modulus of elasticity is obtained for a low alkali concentration at high temperature for a long period with a short drying period at high temperature. These different results show how the treatment parameters strongly affect the mechanical properties of the fiber and therefore why results are so different in the literature. Their statistical study also highlights the fact that combination of factor has generally more influence than factor alone.

For Yu et al. (2009a), the alkali treatment ( $3 \mathrm{~h}$ in $5 \% \mathrm{NaOH}$, dried $72 \mathrm{~h}$ in air and $6 \mathrm{~h}$ in vacuum at $80^{\circ} \mathrm{C}$ ) performs better than the silane treated one and increases tensile strength from 52.5 to $66.8 \mathrm{MPa}$ while the silane treated ones reaches $64.2 \mathrm{MPa}$. A $5 \% \mathrm{NaOH}$ treatment caused no changes in the tensile strength of the composite while the Young's modulus was increased by $29 \%$ in comparison with the untreated one. However, according to Kalia et al. (2009), alkali treatment negatively affects the tensile stress and tensile strength of the fibers while it increases the elongation at break. In general, alkali treated fibers perform better than the 
others. This may be due to the more efficient cleaning of the fibers as this treatment provides a rough surface, which is more likely to interact strongly with the matrix.

\section{Fibers treatment with peroxide}

The peroxide treatment tends to increase the area of the fiber through the creation of cracks and striations (Dittenber and GangaRao 2012), it increases the strain for equivalent stress (Li et al. 2007). According to Aucher (2009), when treated with peroxyde (pretreated with alkaline treatment $1 \mathrm{~h}$ in a $5 \% \mathrm{NaOH}$ mixture, dried $24 \mathrm{~h}$ at $60^{\circ}, 1 \mathrm{~h}$ in $4 \%$ dicumyl peroxide solution), the Ramie/PLA composite show a $41.08 \%$ decrease of its tensile strength when compared to the non-treated composite. Nevertheless, the impact strength and interfacial adhesion were improved with the peroxide treatment. The same effects were observed for fiber by Kalia et al. (2009) with an important decrease of tensile properties while the elongation at break increases for fibers. The peroxide treatment increases the adhesion between Ramie fiber and phenolic resin from 9.6 to 14.9MPa on the IFSS test while it reduces the surface free energy from $63.4 \mathrm{~mJ} / \mathrm{m}^{2}$ to $48.1 \mathrm{~mJ} / \mathrm{m}^{2}$.

\section{Other fibers treatment used for Nettle fibers in a PLA/Nettle composite}

The study reported by $\mathrm{Yu}$ et al. (2014) uses two different concentrations of maleic anhydride (MA) to create a Ramie/PLA composite. The results show that both the tensile strength and the elongation at break reach a maximum with the 3\%MA composite while tensile modulus is maximum for the 5\% MA composite. According to Kalia et al. (2009), another treatment involving acrylic acid is found to increase both tensile strength and stress as well as elongation at break of fibers, but such a positive effect is very rare in the literature. This means that usually, all properties cannot be improved simultaneously and depending on the targeted application, chemical treatments must be carefully chosen. Moreover, Yu et al. (2014) also reports that the fracture behavior can change with maleic anhydride treatment. When not treated, the Ramie/PLA shows a fractured surface on which fiber are relatively clean and empty of resin which is characteristic to the phenomenon of pull-out. At the same time, treated composites show a fractured surface where fibers are pulled out with layers of matrix proving the increased adhesion. Choi and Lee (2012), noticed even if important tensile strength decrease occurred for the composites the chemical treatments do not cause any decrease in of single fibers. It is thought that the treatment causes the fiber to form bundles, therefore lowering the dispersion of the fiber into the matrix. As the different treatments affects fiber's surfaces and interfacial bonding, the global behavior of the composite can be affected.

Some physical treatments also exist. Some of them involve high electrical discharge, (Almeida Mesquita et al. 2017; Bozaci et al. 2013; Matuana et al. 2001; Sarikanat et al. 2014), to modify the surface energy or the structure of the fiber and especially the roughness or the impregnation capabilities (corona, plasma). Other treatment simply consists in drying the fiber to extract moisture and therefore avoid the apparition of micro-voids in the composite. However, chemical treatments are generally preferred and very little literature is available on the physical treatment of Nettle fibers. One major drawback of applying surface treatment on natural fiber is the additional cost of the treatment, which reduces their interest compared to glass fibers for example (Li et al. 2019). 
Biocomposites should be biodegradable or at least compostable (degradable in waste treatment plants), and even if the fibers are extracted from plants, the facts that they are embedded in a polymeric matrix can change the behavior and affect the recyclability of the whole biocomposite. Therefore, some studies evaluate the degradation of the composite when exposed to different environment as oil, compost, water, etc.

To evaluate the evolution of the biodegradability process, weight loss and tensile strength are determined after different periods of time on samples buried in compost maintained at 50\% relative humidity. According to Kumar and Das (2019), the higher the fiber ratio, the higher the loss of weight and tensile strength; up to $25 \%$ and $97.3 \%$ respectively for weight and tensile strength (for a 90/10 PLA/Nettle composite after 20 days buried in soil). In addition, weight loss appears to be linear with respect to fiber ratio, whereas tensile strength appears to be non-linear with respect to fiber ratio and it also appears to decrease more rapidly. This result was clearly predicable but it is interesting to see that mechanical properties decrease when fibers and matrix are degraded by microorganisms. Another study, Akonda et al. (2018), involving 48/52 PLA/flax find that fiber lose 90\% of their mass after a 120 days burial while PLA only loses $10 \%$ of its mass. In all cases, the biggest mechanical loss appears during the 30 first days. Before replacing synthetic composites or conventional materials (Chen and Yan 2020), it may be useful to estimate the impact of using biocomposites through a life cycle assessment Duigou et al. (2011). This would ensure that these biocomposites are fully environmentally friendly.

\section{Effect of oil on biocomposites with Nettle}

There is no study on PLA/Nettle, but the immersion of a PP/Nettle composite in diesel oil showed that mechanical properties were affected with a progressive decrease in tensile strength during the first week (Bajpai et al. 2015). After one week, the effect of oil is stabilized and the final loss in tensile strength remains at $13 \%$.

\section{Effect of UV on biocomposites with Nettle}

When exposed to UV light, the chemical components of the outer layer of the fiber are damaged, resulting in unsightly degradation and loss of structural integrity over long periods (Beg 2008).

According to some authors (Bajpai et al. 2015; Matuana, Kamdem and Zhang 2001; Stark and Matuana 2003) sun exposure of a PP/Nettle laminate results in an $11 \%$ decrease in tensile strength during the first few days, thereafter, the decrease follows a slower but continuous rhythm. This seems to be mainly due to changes in PP behavior from ductile to brittle during initial exposure resulting in interfacial degradation, no investigation have been done with the PLA/Nettle association.

\section{Moisture influence on biocomposites with Nettle}

Bajpai et al. (2015) studied the effect of water immersion (in a river) of a PP/Nettle composite, it leads to delamination of the composite. Results shows a quick drop of tensile properties from $32.56 \mathrm{MPa}$ to $26.01 \mathrm{MPa}$ after $64 \mathrm{~h}$ and then remains more or less constant even after 3 weeks of immersion. This means that moisture certainly impregnates the fiber quickly before reaching saturation. The effect of humidity on fibers is an increased plasticity and a sharp reduction of tensile strength and modulus. The same behavior is described by Pokhriyal et al. (2018) with a PS/Nettle composite exposed in a high moisture environment. As for the 
previous study, the absorption rate is faster at the beginning than after a few days where it reaches saturation.

\section{Manufacturing/processing of the PLA/Nettle composite}

There are not many recent works given indications on how to make a PLA/Nettle biocomposite. To shape composite materials, different methods can be used to assemble the different components to obtain a material as homogeneous as possible. For the elaboration of composite materials based on vegetable fibers, the choice of the technique used, and the operating conditions will have a direct impact on the mechanical properties of the elaborated composite (Sengupta et al. 2007). Extrusion and injection molding do not seem the most suitable because the interest of Nettle fibers lies in their rigidity and therefore their length; so cutting them into microparticles makes them lose advantages of mechanical strength, not to mention the practical difficulties due to the fibers presence that can clog the press (Ilczszyn F. 2013). Resin transfer molding (RTM, a low-pressure injection molding) or pultrusion are other usable shaping methods (Lepetit A. 2017), but compression molding seems to be the most suitable. For example, for Kumar et al. (2017) and Couture et al. (2016), Nettle biocomposites are manufactured by a manual lamination technique, it is performed using a mold and a heating press, for a given cycle, to obtained plates or a fibrous biocomposite intended for door panels realization of car for example.

\section{Conclusion, common uses of biocomposite materials in automotive industry}

Even if they are still in development, biocomposite materials have found their way into the market. In the field of transport, for the automotive industry, weight is the enemy; Henry Ford already knew it in 1942 and therefore successfully replaced metal by hemp fiber composite in its prototype with a $33 \%$ weight reduction. But high production costs left this car as a prototype (Loureiro and Esteves 2019). Nowadays, biocomposites are largely used in the automotive industry since the early 2000's especially because of their lightweight as they could help to cut the final weight of an auto-body by $30 \%$, in comparison with an optimized steel auto-body and by 50\% to 67\% for a standard steel auto-body (Faruk et al 2012; Koronis et al. 2013). The use of composite materials could even be $40 \%$ lighter than their plastic injection molded counterparts according to BMW (Holbery and Houston 2006). Early uses of biocomposite materials in the automotive industry in the 90's involved biofibers and petroleum-based matrix as epoxy resin or polypropylene. This helped to quickly spread them in the industry, but industrial process has increased quantity at the expense of quality (Beardmore 1986). However, growing concerns around global warming push to seek for even more biobased materials. Generally, biocomposite materials are used to make door panels, seat backs, dashboard, spare tire covers, sunroof sliders or other mostly non-structural internal parts (Ashori 2008; Faruk et al. 2012; Ho et al. 2012; Verma and Senal 2019). This greatly helps to improve recyclability of automotive interior parts, especially since the recycling part of their life is neutral in $\mathrm{CO}_{2}$ emission as the combustion process emits as much $\mathrm{CO}_{2}$ as they absorb during growth (Summerscales 2010a, 2010b). However, as claimed by Mercedes Benz (1996), "natural material must be cheaper and, if possible, better than the material that it is replacing". For now, most application of natural fiber are dedicated to non-structural materials, but recent studies show that biocomposite materials could be used as structural parts and even for safety parts as they can absorb a lot of energy through deformation and are therefore crashworthy (Alkbir et al. 2016). This last point need more study as Oshkovr et al. (2012) have found that biocomposite are not as crashworthy as metals due to low plastic 
deformation and the associated weak behavior, but the composite studied here was a epoxy/silk on the contrary to the Epoxy/flax composite in (Alkbir et al. 2016). It is suggested in (Beardmore 1986) that the lower rigidity of biocomposite could be compensated by a higher thickness. Biocomposite could also replace usual composite in car bumper if performances continue to improve (Liu et al. 2016). However, such industrial use of biocomposite in the automotive industry still need improvement as faster fabrication process (around 3 to 4min) with good reproducibility and functional durability (Beardmore 1986). This allows its use only for high-end models. Porsche has, for example, developed a model with doors and tailgate in natural fiber (cayman 718 GT4CS). MacLaren has also developed a seat in linen fiber.

The use of Nettle fiber, on this industrial scale, does not exist yet. The aircraft industry also begins to use biocomposite for interior paneling and they are also more commons in our daily lives through tables, chairs, window frames for other usual furniture. They are also used in sports items like tennis racket, bicycle frames or snowboard (Ho et al. 2012) and even if a certain instability can exist between the composition of the Nettle stems and thus of the fibers of the same field (variability in terms of crystallinity, variation of the angle of the microfibrils, fineness, porosity, size/shape of the lumen,...) as for many other vegetable fibers, there are various means of palliating these disadvantages (mechanical or chemical treatment) and of making it possible to optimize a new entirely biodegradable composite which would be resulting from a PLA/Nettle composition. The intrinsic properties of the Nettle fiber (rigidity, lightness) associated with a rigorous shaping (according to the rate of fiber, its length, the temperature process) promise a real future to this association.

\section{Conflicts of Interest}

The authors declare that they have no conflicts of interest to report regarding the present study.

\section{References}

Abbès, B., Lacoste, C., Bliard, C., Maalouf, C., Simescu-Lazar, F., Bogard, F., Polidori, G. 2020. Novel Extruded Starch-Beet Pulp Composites for Packaging Foams. Materials 13:1571 doi:10.3390/ma13071571.

Akonda M., Alimuzzaman S., Shah D.U., Masudur Rahman A.N.M. 2018. PhysicoMechanical, thermal and Biodegradtion Performance of Random Flax/Polylactic Acid and Unidirectional Flax/Polylactic Acid Biocomposites. Fibers 6(4):98.

Alkbir M.F.M., Sapuan S.M., Nuraini A.A., Ishak M.R. 2016. Fiber properties and crashworthiness parameters of natural fiber-reinforced composite structure: A literature review. Composite Structures 148:59-73 doi:10.1016/j.compstruct.2016.01.098.

Allais, D. 2009. L'ortie dioïque, L'imagerie médicale, 48(490):53-55.

Ashori, A. 2008. Wood-plastic composites as promising green-composites for automotive industries. Bioresource Technology 99(11):4661-4667 doi:10.1016/j.biortech.2007.09.043.

Astruc, J. 2018. Extraction et comptabilisation de nanocristaux de cellulose issus de résidus lignocellulosiques pour le renforcement de biocomposites, Thesis, Sherbrooke University, Canada. 
Aucher J. 2009. Etude comparative du comportement de composites à matrice thermoplastique ou thermodurcissable. Thesis, INSA de Rouen, France.

Bacci, L., Baronti, S., Predieri, S., Di Virgilio, N. 2009. Fiber yield and quality of fiber Nettle (urtica dioica) cultivated in Italy. Industrial Crops and Products 29(2-3):480-484. doi:10.1016/j.indcrop.2008.09.005.

Bacquaert, P. 2013. Les Orties, Institut de recherche du bien-être de la médecine et du sport santé (IRBMS), https://www.irbms.com/les-orties/ .

Bajpai P.K., Meena D., Vasta S., Singh I. 2015. Tensile behavior of Nettle fiber composites exposed to various environments. Journal of Natural Fibers 10(3):244-256.

Baley C., Morvan C., Grohens Y. 2005b. Influence of the absorbed water on the tensile strength of flax fibers. Macromolecular Symposia 222:1552-596.

Baley, C. 2002a. Analysis of the flax fibres tensile behaviour and analysis of the tensile stiffness increase. Composites Part A: Applied Science and Manufacturing 33:939-948 doi:10.1016/S1359-835X(02)00040-4.

Baley, C. 2013c. Fibres naturelles de renfort pour matériaux composites. Techniques de l'ingénieur, Matériaux composites : présentation et renforts AM5130(2):1-17.

Barbulée, A. 2015. Compréhension des effets du défibrage sur la morphologie, les propriétés et le comportement mécanique des faisceaux de fibres de lin. Etude d'un composite dérivé lin-époxyde, Thesis, Université de Basse Normandie, Caen, France.

Barral, M., Chatzigeorgiou, G., Meraghni, F. 2019. Homogénéisation par approche TFA intégrée au schéma de mori-Tanaka pour les composites élastoplastiques /viscoélastiques/ viscoplastiques: Théorie et validation numérique. Journées Nationale sur les composites, Bordeaux, France.

Beardmore, P.J.C. 1986. The potential for composites in structural automotive applications. Composites Science and Technology 26(4):251-281 doi:10.1016/0266-3538(86)90002-3.

Beg M. H. 2008. Reprocessing of wood fibre reinforced polypropylene composites. Part I: Effects on physical and mechanical properties. Composites Part A: Applied Science and Manufacturing 39(7):1091-1100.

Bergfjord, C., Holst, B. 2010. A procedure for identifying textile bast fibres using microscopy: Flax, Nettle/Ramie, hemp and jute. Ultramicroscopy 110:1192-1197.

doi:10.1016/j.ultramic.2010.04.014.

Bledzki, A.K., Gassan, L. 1999. Composites reinforced with cellulose based fibres. Progress in Polymer Science 24:221-274. doi:10.1016/S0079-6700(98)00018-5.

Bodros, E., Baley, C. 2008. Study of the tensile properties of stinging Nettle fibres (Urtica dioica). Materials Letters 62:2143-2145 doi:10.1016/j.matlet.2007.11.034.

Bouzouita, S. 2011. Optimisation des interfaces fibre-matrice de composites à renfort naturel, Thesis, Ecole Centrale de Lyon, Ecole Nationale d'ingénieurs de Monastir, Tunisia.

Bozaci E., Sever K., Sarikanat M., Seki Y., Demir A., Ozdogan E., Tavman I. 2013. Effects of the atmospheric plasma treatments on surface and mechanical properties of flax fiber and adhesion between fiber-matrix for composite materials. Composites Part B: Engineering 45(1):565-572 doi:10.1016/j.compositesb.2012.09.042.

Broohm, A. 2018. Homogénéisation du comportement élastique des composites avec la prise en compte de l'endommagement, Thesis, Université Paul Verlaine, France.

CARMA. 2006. Glossaire des matériaux composites renforcés de fibres d'origine renouvelable, http://gaetanmabille.free.fr/ecoconception/glossaire\%20composites\%20biodegradables\%2 0_CARMA.pdf.

Chen X., Ren J., Zhang N., Gu S., Li J. 2014a. Effects of heat treatment on the thermal and mechanical properties of fabric-reinforced PLA bio composite. SAGE journals 34(1):2836.

Chen X., Yan N. 2019b. A brief overview of renewable plastics. Material Today Sustainability 7(8):100031 doi:10.1016/j.mtsust.2019.100031. 
Chen Y., Chiparus O., Sun L., Negulescu I., Parikh D.V., Calamari T.A. 2005. Natural Fibers for automotive Nonwoven Composites. Journal of Industrial Textiles 35:47-62.

Chevalier M. 1975. Moulage des matières thermodurcissables. Techniques de l'Ingénieur, Compression Transfert Injection 1(A3741):1-12.

Choi H.Y., Lee J.S. 2012. Effects of surface treatment of Ramie fibers in a Ramie/Poly(lactic acid) composite. Fibers and Polymers 13(2):217-223.

Cisneros-Lopez E.O., Pal A.K., Rodriguez A.U., Wu F., Misra M., Mielewski D.F., Kiziltas A., Mohanty A.K. 2019. Recycled poly(lactic acid)-based 3D printed sustainable biocomposites: a comparative study with injection molding. Material Today Sustainability 7(8):100027. doi:10.1016/j.mtsust.2019.100027.

Coppo, I., Pino Munoz, D., Bernacki, M., Bouvard, J.L., 2017. Génération de VERs et calculs d'homogénéisation : application aux composites thermoplastiques à renforts discontinus, French Mechanical Congress.

Couture A., Lebrun, G., Laperriere L., 2016. Mechanical properties of PLA composite reinforced with unidirectional fax and flax-paper layers. Composite structures. 154:286295.

Daimler-Benz Environmental Report. 1996. Stinging Nettles: a promising reinforcement for plastics. Reinforced Plastics 40(11):16.

Davies G.C., Bruce D.M. 1998. Effect of relative humidity and damage on the tensile properties of flax and Nettle fibers. Textile Research Journal 68(9):623-629.

de Almeida Mesquita R.G., da Silva César A.A., Mendes R.F., Mendes L.M., Marconcini J.M., Glenn G., Tonoli G.H.D. 2017. Polyester Composites Reinforced with CoronaTreated Fibers from Pine, Eucalyptus and Sugarcane Bagasse. Journal of Polymers and the Environment 25:800-811.

Di Virgilio, N., Papazoglou, E.G., Jankauskiene, Z., Lonardo, S., Praczyk, M., Wielgusz, K. 2015. The potential of stinging Nettle (Urtica dioica L.) as a crop with multiple uses. Industrial Crops and Products 68:42-49 doi:10.1016/j.indcrop.2014.08.012.

Dicker, M.P.M., Duckworth, P.F., Baker, A.B., Francois, G., Hazzard, M.K., Weaver, P.M. 2014. Green composites: A review of material attributes and complementary applications. Composites: Part A 56:280-289 doi:10.1016/j.compositesa.2013.10.014.

Dittenber D.B., GangaRao H.V.S. 2012. Critical review of recent publications on use of natural composites in infrastructure. Composites: Part A 43:1419-1429.

Do Thi, V. 2011. Matériaux composites à fibres naturelles / polymère biodégradables ou non, Thesis, Université de Grenoble, France.

Draghy, F. 2005. L'ortie dioïque (Urtica dioica L.) : étude bibliographique. Sciences pharmaceutiques hal-01733415.

Du, Y., Yan, N., Kortschot, MT. 2015. The use of Ramie fibers as reinforcements in composites. Biofiber Reinforcements in Composite Materials ISBN978-1-78242-122-1, 104-137 doi:10.1016/C2013-0-16470-7.

Duigou A., Davies P., Baley C. 2011. Environmental Impact Analysis of the Production of Flax Fibres to be used as composite material reinforcement. Journal of Biobased Materials and Bioenergy 5:1-13.

Eichhorn, S.J., Baillie, C., Zafeiropoulos, N., Mwaikambo, L.Y., Ansell, M.P., Dufresne, A., Entswistle, K.M., Herrera-Franco, P., Canché-Escamilla, G., Groom, H., Hughes, M., Hill, C.A.S., Rials, T., Wild, P.M. 2001. Review: Current international research into cellulosic fibres and composites. Journal of Materials Sciences 36(9):2107-2131 doi:10.1023/A:1017512029696.

Eshelby, J. 1957. The determination of the elastic field of an ellipsoidal inclusion, and related problems. Proceedings of the Royal Society of London, Series, Mathematical and Physical Science 241(1226):376-396.

Faruk, O., Bledzki, A., Fink, H.P., Sain, M. 2012. Biocomposites reinforced with natural fibers: 2000-2010. Progress in Polymer Science 37(11):1552-1596 doi:10.1016/j.progpolymsci.2012.04.003. 
Fischer, H., Werwein, E., Graupner, N. 2012. Nettle fibre (Urtica dioica L.) reinforced poly(lactic acid): A first approach. Journal of Composite Materials 46(24):3077-3087. doi:10.1177/0021998311435676.

Frollini E., Leao A., Mattoso L.H.C., Rowell R., Han J., Rowell J. 2000. Characterization and factors effecting fiber properties, Natural Polymers and Agro fibers composites. https://www.researchgate.net/publication/237255433_Characterization_and_Factors_Effec ting_Fiber_Properties .

Gehring F. 2013. Etude du comportement mécanique et de l'endommagement de composites thermoplastiques renforcés de fibres courtes de chanvre: Approche expérimentale et modélisation. Thesis, Université de Lorraine, France.

Girard, G., Jrad, M., Bahi, S., Martiny, M., Mercier, S., Bodin, L., Nevo, D., Dareys, S. 2017 Caractérisations expérimentale et numérique de composites minces tramés utilisés dans les circuits imprimés pour des applications hyperfréquences. French Mechanical Congress.

Godin B., Agneessens R., Gofflot S., Lamaudière S., Sinnaeve G., Gerin P., Delcarte J. 2011. Revue bibliographique sur les méthodes d'analyse des polysaccharides structuraux des biomasses lignocellulosiques. Biotechnol. Agron. Soc. Environ. 15(1):165-182.

Gourier, C. 2016. Contribution à l'étude de matériaux biocomposites à matrice thermoplastique polyamide-11 et renforcés par des fibres de lin, Thesis, Université de Bretagne Sud, France.

Gurunathan T., Mohanty S., Nayak S.K. 2015. A review of the recent Developments in Biocomposites Based on Natural Fibres and Their Application Perspectives. Composites Part A: Applied Science and Manufacturing 77:1-25.

Hassler, M. 2018. World Plants: Synonymic Checklists of the Vascular Plants of the World, www.catalogueoflife.org/col.

Hearle J.W.S. 1963. The fine structure of fibers and crystalline polymers. III. Interpretation of the mechanical properties of fibers. Journal of applied polymers Science. 7:1207-1223.

Ho, M.P., Wang, H., Lee, J-H., Ho, C., Lau, K., Leng, J., Hui, D. 2012. Critical Factors on Manufacturing processes of natural fibre composites. Composites part B: Engineering 43(8):3549-3562 doi:10.1016/j.compositesb.2011.10.001.

Holbery, J., Houston, D. 2006. Natural-fiber-reinforced polymer composites in automotive applications. The Journal of the Minerals 58(11):80-86 doi:10.1007/s11837-006-0234-2.

Ilczszyn F. 2013. Caractérisation expérimentale et numérique du comportement mécanique des agro-composites renforcés par des fibres de chanvre. Thesis, Université de Troyes, France.

Iron Boar Labs Ltd. 2020. (PLA) l'acide polylactique. https://www.makeitfrom.com/materialproperties/Polylactic-Acid-PLA-Polylactide .

Jacob John M., Anandjiwala R. 2008. Recent Developments in Chemical Modification and Characterization of Natural Fiber-Reinforced Composites. Polymer composites 187-207

Jain, A., Jin, B.C., Nutt, S. 2017. Mean Field homogenization methods for strands composites. Composites Part B: Engineering 124:31-39 doi:10.1016/j.compositesb.2017.05.036.

JEC. 2017. Overview of the global composites market.

Jensen C.U., Rodriguez Guerrero J.K., Karatzos S., Olofsson G., Iversen S.B. 2017. Fundamentals of HydrofactionTM: Renewable crude oil from woody biomass. Biomass Convers. Biorefinery 7(4):495-509.

Ji, H., McLendon, W.R., Hurtado, J.A., Oancea, V., Bi, J. 2017. Multi-scale Modeling with the Mean-Field Homogenization Method. NAFEMS World Congress, Stockohlm.

Kalia, S., Kaith, B.S., Kaur, I. 2009. Pretreatments of natural fibers and their application as reinforcing material in polymer composites - A review. Polymer Engineering and Science 49:1253-1272 doi:10.1002/pen.21328.

Karaky, H., Maalouf, C., Bliard, C., Gacoin, A., Lachi, M., El Wakil, N., Polidori, G. 2019. Characterization of beet-pulp fiber reinforced potato starch biopolymer composites for 
building applications. Construction and Building Materials 203:711-721 doi:10.1016/j.conbuildmat.2019.01.127.

Khatkar V., Behera B.K., Manjunath R.N. 2020. Textile structural composites for automotive leaf spring application. Composites part B: Engineering 182:107662

doi:10.1016/j.compositesb.2019.107662.

Koronis, G., Silva, A., Fontul, M. 2013. Green Composites: A review of adequate materials for automotive applications. Composites: Part B 44:120-127

doi:10.1016/j.compositesb.2012.07.004.

Kritschewsky G.E. 1996. An Introduction to Composite Materials (2nd ed., Cambridge Solid State Science Series). Hull, D., \& Clyne, T. Cambridge University Press.

Kumar N., Das D. 2016a. Alkali treatment on Nettle fibers Part I: investigation of chemical, structural, physical, and mechanical characteristics of alkali-treated Nettle fibers. The Journal of The Textile Institute 108(8):1461-1467.

Kumar N., Das D. 2016b. Alkali treatment on Nettle fibers Part II: design of experiment and desirability function approach to study enhancement of tensile properties. The Journal of The Textile Institute 108(8):1468-1475.

Kumar N., Das D., Neckar B. 2018. Effect of fiber orientation on tensile behavior of biocomposites prepared from Nettle and poly(lactic acid) fibers: Modeling \& experiment. Composites Part B 138:113-121.

Kumar N., Das D. 2019. Fibrous biocomposites from Nettle (Girardinia diversifolia) and poly(lactic acid) fibers for automotive dashboard panel application. Composites Part B 30:54-63.

Kumar S., Mer K.K.S, Gangil B., Patel, V.K., 2020. Synergistic effect of hybrid Himalayan Nettle/Bauhinia-vahlii fibers on physico-mechanical and sliding wear properties of epoxy composites. Defence Technology 16:762-776 doi:10.1016/j.dt.2019.08.006.

Laurans F., Dejardin A., Leple J., Pilate G. 2006. Physiologie de la formation des parois de fibres de bois, Revue des composites et des matériaux avancés 16:25-40.

Lepetit A. 2017. Elaboration de matériaux composites à base de filaments de cellulose et de polyéthylène. Thesis, Université de Limoges, France.

Li, X., Tabil, L.G., Panigrahi, S. 2007. Chemical Treatments of Natural Fiber for Use in Natural Fiber-Reinforced Composites: A Review. Journal of Polymers and the Environment 15:25-33 doi:10.1007/s10924-006-0042-3.

Liu Z., Liu J., Zhu P. 2016. Lightweight design of automotive composite bumper system using modified particle swarm optimizer. Composite Structures 140:630-643.

Lu Y., Weng L., Cao X. 2006. Morphological, thermal and mechanical properties of ramie crystallites-reinforced plasticized starch biocomposites; Carbohydrate. Polymers 63:198204.

Loureiro, N.C., Esteves, J.L. 2019. Green composites in automotive interior parts: a solution using cellulosic fibers. Green Composites for Automotive Application 4:81-97. ISBN:9780081021781 ElsevierScience.

Madsen, B., Thygesen, A., Lilholt, H. 2007a. Plant fibre-porosity and volumetric interaction. Composite Science and Technology 67(7-8):1584-1600 doi:10.1016/j.compscitech.2006.07.009.

Madsen, B., Thygesen, A., Lilholt, H. 2009b. Plant fibre composites-porosity and stiffness, Composites Science and Technology 69(7-8):1057-1069.

Matuana L.M., Kamdem D.P., Zhang J. 2011. Photoaging and stabilization of rigid PVC/wood-fiber composites. Journal of Applied Polymer Science 80(11):1943-50.

Moussaddy, H. 2013. A new definition of the representative volument element in numerical homogeneization problems and its application to the performance evaluation of analytical homogenization models, Thesis, University of Montreal, Canada.

Murariu M., Dubois P. 2016. PLA composites: from production to properties. Advanced Drug Delivery Reviews 107:17-46. 
Mûssig Jörg Editor. 2010. Industrial Applications of Natural Fibres: Structure, Properties and Technical Applications. 87-234 and 290-309. ISBN: 9780470695081

Nabi Saheb, D., Jog, J.P. 1999. Natural Fiber Polymer Composites: A Review. Advances in Polymer technology 18(4):351-353 doi:10.1002/(SICI)1098-2329(199924).

Nguyen D. 2016c. Caractérisation de l'interface fibre/matrice. Application aux composites polypropylène/chanvre. Thesis, Université de Technologies de Troyes, France.

Nguyen T., Zavarin E., Barrall E.M. 1981a. Thermal Analysis of Lignocellulosic Materials: Modified Materials. Journal of Macromolecular Science, Part C, Polymer review 21:1-60.

Nguyen T., Zavarin E., Barrall E.M. 1981b. Thermal Analysis of Lignocellulosic Materials: Unmodified materials Journal of Macromolecular Science, Part C, Polymer review 20:165.

Notta-Cuvier D., Bouzouita A., Odent J., Delille R., Murariu M., Lauro F., Raquez J.M., Haugou G., Dubois P. 2018. L'acide polylactique (PLA) pour des applications automobiles. Techniques de l'Ingénieur, Matériaux Plastiques et composites RE273v1:114.

Ogunsona, E.O., Codou, A., Misraa, M., Mohanty, A.K. 2019. A critical review on the fabrication processes and performance of polyamide biocomposites from a biofiller perspective. Material Today Sustainability 5:100014 doi:10.1016/j.mtsust.2019.100014.

Ojogbo, E., Ogunsona, E.O., Mekonnen, T.H. 2020. Chemical and physical modifications of starch for renewable polymeric materials. Material Today Sustainability 7(8):100028 doi:10.1016/j.mtsust.2019.100028.

Oshkovr S.A., Eshkoor R.A., Taher S.T., Ariffin A.K., Azhari C.H. 2012. Crashworthiness characteristics investigation of silk/Epoxy composite square tubes. Composite Structures 94:2337-2342.

Peijs T., Melick V., Garkhail S.K., Pott G.T., Baillie C.A. 1998. Natural-fibre-mat reinforced thermoplastics based on upgraded flax fibres for improved moisture resistance. ECCM-8 conference 119-26, Naples, Italy.

Penu C., Helou M. 2017. Acide polylactique (PLA). Techniques de l'Ingénieur, Matériaux Plastiques et composites AM3317:1-14.

Pokhriyal M., Prasad L., Rakesh P.K., Raturi H.P. 2018. Influence of fiber loading on physical and mechanical properties of Himalayan Nettle fabric reinforced polyester composite. Materials Today: Proceedings 5:16973-16982.

Raj M., Fatima S., Tandon N. 2020. An experimental and theoretical study on environmentfriendly sound absorber sourced from Nettle fibers. Journal of Building Engineering 31:101395 doi:10.1016/j.jobe.2020.101395.

Rehman, M, Gang, D., Liu, Q., Chen, Y., Wang, B., Peng, D., Liu, L. 2019. Ramie a multipurpose crop: potential applications, constraints and improvement strategies. Industrial Crops and Products 137:300-307 doi :10.1016/j.indcrop.2019.05.029.

Rouch, M. 2018. Contribution à la compréhension des mécanismes de vieillissement hydrothermique de matériaux composites unidirectionnels polyesters insaturé/fibre de lin, Thesis, Université de Normandie, France.

Sanjay M. 2018. Characterization and properties of natural fiber polymer composites: a comprehensive review. Journal of Cleaner Production 172:566-581.

Sarikanat M., Seki Y., Sever K., Bozaci E., Demir A., Ozdogan E. 2014. The effect of argon and air plasma treatment of flax fiber on mechanical properties of reinforced polyester composite. Journal of Industrial textiles 45(6):1252-1267 doi:10.1177/1528083714557057.

Sengupta R., Chakraborty S., Bandyopadhyay S., Dasgupta S., Mukhopadhyay R., Auddy K., et al., 2007. A Short Review on Rubber / Clay Nanocomposites With Emphasis on Mechanical Properties. Engineering 47:21-25.

Shahzad, A. 2017. Mechanical properties of lignocellulosic fiber composites. Lignocellulosic fibre and biomass-based composite materials, Woodhead Publishing Series in Composites Science and Engineering 193-223. ISBN 9780081009666. 
Söderguard A., Mickael S. 2002. Properties of lactic acid based polymers and their correlation with composition. Progress in Polymer Science 27(6):1123-1163.

Stark N.M., Matuana L.M. 2003. Ultraviolet weathering of photostabilized woodflour-filled high-density polyethylene. Journal of Applied Polymer Science 90(10), 2609-17.

Sudamrao Getme, A., Patel, B.A. 2020. Review: Bio-fiber's as reinforcement in composites of polylactic-acid (PLA). Materials Today: Proceedings 26:2116-2122. doi:10.1016/j.matpr.2020.02.457.

Summerscales, J. 2010b. A review of bast fibres and their composites. Part 2 - Composites. Composites Part A: Applied Science and Manufacturing 41(10):1336-1344. doi:10.1016/j.compositesa.2010.05.020.

Summerscales, J., Dissanayake, N.P.J., Virk, A.S., Hall, W. 2010a. A review of bast fibres and their composites Part 1 - Fibres as reinforcements. Composites: Part A 41:1329-1335 doi:10.1016/j.compositesa.2010.06.001.

Thilgavathi G., Karan C.P. 2019. Investigations on oil sorptions capacity of Nettle fibrous assembly and 100\% Nettle and Nettle/kapok blended needle punched nonwovens. Journal of Industrial Textiles 49(4):415-430.

Torres, J.P., Vandu, L.J., Veidt, M., Heitzmann, M.T. 2017. The mechanical properties of natural fibre composite laminates: a statistical study. Composites Part A: Applied Science and Manufacturing 98:99-104 doi:10.1016/j.compositesa.2017.03.010.

Tucker III, C.L., Liang, E. 1999. Stiffness predictions for unidirectional short-ber composites: Review and evaluation. Composites Science and Technology 59:655-671. doi:10.1016/S0266-3538(98)00120-1.

Thwe M., Liao K. 2002. Effects of environmental aging on the mechanical properties of bamboo-glass fiber reinforced polymer matrix hybrid composites. Composites: Part A $33: 43-52$

Upton, R. 2013. Stinging nettles leaf (Urtica dioica L.): Extraordinary vegetable medicine. Journal of herbal medicine 3:9-38.

Van Soest P., Robertson J., 1985. Analysis of forages and fibrous foods. Ithaca editor, Department of Animal Science, Cornell University, USA.

Verma, D., Senal, I. 2019. Natural fiber-reinforced polymer composites. Biomass, Biopolymer-Based Materials and Bioenergy 6:103-122 doi:10.1016/B978-0-08-1024263.00006-0.

Wang Y., Guangpeng C., Zhujian S., Yongjie B., Gao H. 2019. Optimization of the Hot pressing process for preparing flax/PE thermoplastic composite. Mechanical Engineering Science 1(1):56-62.

Xu H., Liu C., Chen C., Hsiao B.S., Zhong G., Li Z. 2012. Easy alignment and effective nucleation activity of Ramie fibers in injection- molded poly(lactic acid) biocomposite. Biopolymers 97(10):825-839.

Yu T., Jiang N., Li Y. 2014b. Study on short Ramie fiber/poly(lactic acid) composites compatibilized by maleic anhydride. Composites: Part A 64:139-146.

Yu T., Li Y., Ren J. 2009a. Preparation and properties of short natural fiber reinforced poly(lactic acid) composites. Transactions of Nonferrous Metals Society of China 19:651655.

Yu T., Ren J., Li S., Yuan H., Li Y. 2010c. Effect of fiber surface-treatments on the properties of poly(lactic acid)/Ramie composites. Composite : Part A 41:499-505.

Zhi Rong M., Zhang M., Liu Y., Yang G., ZengH. 2001. The effect of fiber treatment on the mechanical properties of unidirectional sisal-reinforced epoxy composites. Composites Science and Technology 61:1437-1447. 